\title{
Biodiversity reporting in Sweden: corporate disclosure and preparers' views
}

Article

Accepted Version

Rimmel, G. and Jonäll, K. (2013) Biodiversity reporting in Sweden: corporate disclosure and preparers' views.

Accounting, Auditing \& Accountability Journal, 25 (5). pp. $746-$ 778. ISSN 0951-3574 doi: https://doi.org/10.1108/AAAJ-022013-1228 Available at https://centaur.reading.ac.uk/73608/

It is advisable to refer to the publisher's version if you intend to cite from the work. See Guidance on citing.

To link to this article DOI: http://dx.doi.org/10.1108/AAAJ-02-2013-1228

Publisher: Emerald

All outputs in CentAUR are protected by Intellectual Property Rights law, including copyright law. Copyright and IPR is retained by the creators or other copyright holders. Terms and conditions for use of this material are defined in the End User Agreement.

\section{www.reading.ac.uk/centaur}

\section{CentAUR}

Central Archive at the University of Reading

Reading's research outputs online 


\section{Introduction}

Sweden, which is blessed with extraordinary natural resources, is famous for its flora and fauna. It is a country of vast forests, numerous lakes, rugged, high alpine mountains, and glaciers, as well as 221831 islands (SCB, 2009). The UNESCO World Heritage site lists 14 Swedish national parks because of their rich natural assets (UNESCO, 2010). Wild animals such as moose, wolverines, wolves, lynxes and brown bears live in the Swedish forests and mountains. Moreover, one of the oldest animal species in the world, the shaggy giant ox, lives in the wild area of Härjedalen in north-western Sweden (SEPA, 2011).

"We walk in the steps of our forefathers, leaving no trace behind us" (Visit Sweden.com, 2011-10-19).

Despite the Swedish tourism office's glowing depiction of the rich biodiversity of the country, there are less attractive aspects. The paper industry engages in intensive harvesting of trees in the forests that cover around $65 \%$ of Sweden's total land area. In recent years, there has been significant media attention on Naturskyddsföreningen (Swedish Society for Nature Conservation - SSNC). ${ }^{2}$ In its collaboration with Greenpeace, SSNC filed a joint formal complaint against the listed Swedish company, Svenska Celluosa (SCA). The complaint concerned clear-cut logging in northern Sweden, which is a violation of the Forest Stewardship Council (FSC) standards for sustainable forestry (SSNC, 2010).

In the formal complaint to the FSC, SSNC and Greenpeace Nordic criticized SCA for clear-cut logging in boreal forests areas without consideration for the small habitats with special biodiversity needs. In such habitats, 39 Red-Listed species have been found (SSNC, 2010). Furthermore, the complaint charged that Swedish legislation and FSC certification have failed to safeguard the biological value of the forest ecosystem, thus diminishing its biodiversity (SNCC, 2011).

From an accounting research perspective, the development of social and environmental accounting has been a matter of concern for more than 40 years. To date, there are a number of accounts of companies' effect on the environment and on society (Gray, 2010). There is also an extensive and growing body of research that examines companies' disclosures that deal with these issues. However, there is little research that has investigated companies' motivations for providing such information (Unerman, 2008). Gray (2010) questions whether the general level of inquiry in current research on accounting for sustainability is actually accounting for sustainability.

In response to Gray's (2010) concern, this article aims to add to the accounting research on sustainability issues with its more specialised and detailed inquiry. The recent biological catastrophes after British Petroleum's (BP) oil spill in the Gulf of Mexico may be a reference point that highlights the grave risks of corporate biodiversity stewardship. However, ecological disasters, corporate reputational damage and financial losses may not necessarily lead to improved biodiversity stewardship. Before BP's Deepwater Horizon incident, there were many other serious environmental incidents such as the Exxon Valdez oil spill in Alaska and the Shell oil spill in the Niger Delta. There was a media outcry after each of these incidents. Highly emotional images of oil polluted coastlines and landscapes and of dying animals and seabirds were shown in television broadcasts, accompanied by interviews with

\footnotetext{
${ }^{1}$ This is the front-page headline under the category "Eco-Tourism in Sweden" on Sweden's official website for tourism and for travel information.

${ }^{2}$ Naturskyddsföreningen (Swedish Society for Nature Conservation - SSNC) is an environmental, nonprofit organization (NGO) that addresses environmental threats in Sweden and tries to create environmental awareness among public authorities, at both national and international levels.
} 
environmental groups. However, as time goes by, the media focuses on other events, and these incidents fade from memory.

Although these oil spills severely damaged local biodiversity, it is not the intention of this article to explore the disclosure extremes that followed these catastrophes. The aim of the article is to explore that status of biodiversity disclosure by multinationals listed on the Swedish stock exchange.

The research questions of this article are the following:

(i) What is the extent of biodiversity disclosure by Swedish multinationals?

(ii) Where do these companies present their biodiversity disclosure?

(iii) Why do these companies make their biodiversity disclosure?

In addition to an explorative, descriptive study of the quantity and location of biodiversity disclosure in a Swedish setting, using a mixed methods approach, this article also presents comments from interviews with company representatives regarding company intentions behind their biodiversity disclosure.

The remainder of this article is structured as follows. First, in the literature review section, the article presents a definition of the biodiversity crisis as a World Conservation Union (IUCN) category. In order to understand the Swedish context, a description of the institutional setting provides an overview of the influence that international policy by the United Nations (UN) and the European Union (EU) exerts on Swedish biodiversity policy. Thereafter, the limited stream of studies that focus on biodiversity accounting and reporting is reviewed. In the research methodology section, the article argues that in order to understand the quantity and location of biodiversity disclosure, interviews with company representatives should be conducted. Such interviews can provide insight into the intentions behind disclosure. The results section presents the quantity and location of biodiversity disclosure as interpreted in the light of the interviews. Finally, the concluding discussion deals with the low biodiversity disclosure in the five-year research period, and the preparers' comments on their disclosure motivation. This discussion is in the context of the on-going debate on corporate reporting practices.

\section{Literature review}

The purpose of this section is threefold. First, it draws on the multiple definitions of biodiversity and the context of the biodiversity crisis. Second, because biodiversity is an important issue in environmental politics, a brief overview is provided of international and Swedish institutions that are involved in the institutional setting of biodiversity. Third, a brief review of the very limited research on biodiversity in accounting research is presented.

\subsection{The crisis facing biodiversity}

There are a number of definitions of biological diversity, or, as it is frequently termed, biodiversity. According to Waldman and Shevah (2000), these definitions refer to the variety and variability of living organisms, their habitats and their biological ecosystems, including the ecological and evolutionary processes in the natural environment. Consequently, biodiversity is a universal term that draws on the uniqueness of the biological world but also reflects the variety of all the Earth's life forms and natural processes. 
The Convention on Biological Diversity (CBD) defines biodiversity as:

"the variability among living organisms from all sources [...] this includes diversity within species, between species and of ecosystems" (Article 2; CBD, 1992).

The term biodiversity per se is not restricted to the preservation of particular endangered species or to the conservation of threatened ecosystems ${ }^{3}$ that place ecosystem services ${ }^{4}$ at risk. Commonly, biodiversity includes the genetic diversity that produces characteristics, the evolutionary resilience and adaptability to change, and species diversity as well as the interactions between species and ecosystems (EAA, 2010).

In 2008, the economics of ecosystems and biodiversity (TEEB) study was presented at the 9th meeting of the Conference of the Parties to the CBD. In its presentation of findings from numerous studies, the TEEB report demonstrated that biodiversity is in crisis. The report stated that the well-being of humanity is fundamentally and directly dependent on the Earth's ecosystem services (TEEB, 2008). Wilkinson's study (2004) revealed that fishing, pollution, disease and coral bleaching have damaged $30 \%$ of the world's coral reefs. These reefs have some of the highest level of biodiversity on Earth. Moreover, the rate of species extinction caused by humans is estimated to be 1,000 times faster than the typical rate of extinction in the history of the Earth (Millennium Ecosystem Assessment, 2005).

In order to illustrate the crisis state of biodiversity and its environmental impact, many organizations and reports use the Red List terminology. In 2010, the Swedish Species Information Centre (SSIC) published its Swedish Red List based on the IUCN classification system for threatened and rare species. The Swedish Red List groups species into six categories based on their risk of extinction. These six categories are the same as the Red List categorization in the Global Reporting Initiative (GRI), where it is one of the key performance biodiversity indicators. The first Red List category is Near Threatened (NT), which is a category for species that may be threatened in the future. Vulnerable (VU) is the first of the three threatened categories on the Red List, followed by Endangered (EN) and Critically Endangered (CR). The category Regionally Extinct (RE) includes those species that have disappeared. The category Data Deficient (DD) is for all other categories in which insufficient information is available (SSIC, 2010). Like the IUCN list, the six Swedish categories as well as the GRI indicators indicate no priorities for conservation action. However, there is a seventh category, the Least Concern (LC), which is not a Red List category because the number of species in the category is considered sufficient for survival.

\subsection{Environmental accounting and biodiversity disclosure}

It is widely acknowledged that increased environmental awareness, global inequalities and social questions have led to an extensive body of academic accounting studies on corporate social responsibility (CSR) (e.g., Gray et al., 1993; Gray et al., 1995; Hackston and Milne, 1996; Adams, 2004, 2008; Unerman, 2008; Archel et al., 2009; Gray, 2010; Henri and Journeault, 2010). In the past 40 years, different streams of research have focused on numerous issues and features of social and environmental reporting (SER), ranging from studies on reporting and disclosing sustainability measures to studies on practices and

\footnotetext{
3 "Ecosystem" refers to a dynamic complex of plant, animal and micro-organism communities and their non-living environment in interaction as a functional unit (Article $2-\mathrm{CBD}, 1992$ ).

${ }^{4}$ Ecosystem services are the benefits that people obtain from ecosystems. Examples include food, fresh water, timber, climate regulation, protection from natural hazards, erosion control, pharmaceutical ingredients and recreation. Biodiversity is not itself an ecosystem service, but it supports the supply of services (TEEB, 2008).
} 
perceptions of managerial capture (Gray et al., 1998). Several attempts have been made to review and map the existing body of literature (e.g., Thomson, 2007; Burritt and Schaltegger, 2010). Many academic SER studies have been motivated by a concern for the natural environment (see Milne, 1991, 1996; Milne and Gray, 2007; Gray, 2010).

An examination of the development of accounting research on social and environmental issues reveals that the term sustainability in corporate disclosures is vaguely used (e.g., Tregidga and Milne, 2006; Adams and Larrinaga-González, 2007; Farneti and Guthrie, 2009). A critical analysis of corporate sustainable reporting by Milne et al. (2009) showed that companies might take a narrow economic and instrumental approach to the environment. Due to the complexity of SER practices, a number of researchers recommend that SER be studied in-depth in order to help us understand the roles of its specific issues (e.g., Adams, 2008; Bebbington et al., 2008; Unerman, 2008).

One example that shows how specific international environmental politics influence accounting regulations intended to report on economic interests in the environment is the Financial Accounting Standards Board's (FASB) environmental regulation and reporting project. Another such example is the International Accounting Standards Board's (IASB) regulations on emissions trading schemes. ${ }^{5}$ These regulations and projects may have stimulated academic research activities in this area because accounting researchers closely monitor the actions of the accounting standard setters (Larrinaga-Gonzales and Bebbington, 2001; Bebbington and Larrinaga-Gonzales, 2008).

Accounting researchers, however, have not paid a great deal of attention to the specific elements of the biodiversity crisis. Only a few accounting research studies address the crisis (e.g., Jones, 1996, 2003; Jones and Matthews, 2000; Houdet, 2008: Houdet et al., 2009; Grabsch et al., 2010). Jones's (1996, 2003) biodiversity reporting framework consists of a three-stage natural inventory model for recording, valuing and reporting biodiversity. Houdet (2008) focuses on establishing an accountability framework for biodiversity, which is a management style accounting system that links economic operations to eco-systems using a number of indicators. Interest in biodiversity by the capital markets was evident in the F\&C Asset Management (2004) report titled "Is biodiversity a material risk for companies? An assessment of the exposure of FTSE sectors to biodiversity risk". This report developed a methodology that assigns the biodiversity risk level for each sector represented on the London Stock Exchange (FTSE) into one of three groups: red, amber or green. The F\&C classification system is as follows:

- The red-zone sectors are those in which most companies are likely to be exposed to biodiversity risks and in which risks are likely to be significant.

- The amber-zone sectors are those in which some companies are likely to be exposed to biodiversity risks and in which risks may be significant.

- The green-zone sectors are those in which fewer companies are likely to be exposed to biodiversity risks and in which it is are harder to identify how risks may affect the companies. .

The F\&C report examined the biodiversity risks that the FTSE sectors are exposed to and concluded that biodiversity disclosure is directly relevant to the capital markets' assessment of companies' value.

\footnotetext{
${ }^{5}$ Currently, this project is on hold until the IASB concludes its on-going deliberations about its future work plan.
} 
An increasing number of listed multinational companies apply SER frameworks like GRI Reporting Framework, as recommended by UN Global Compact (UNGC), for reporting their SER disclosure to stakeholders. In the GRI Guidelines (2011), six indicators specifically deal with biodiversity disclosure (see Table 1).

Insert Table 1 about here

According to the GRI (2011), two biodiversity indicators, EN11 and EN12, are highlighted as core biodiversity indicators. Three other biodiversity indicators, EN13, EN14 and EN15, are presented as additional indicators. An examination of the GRI Indicator Protocol shows that even EN25 on water-related biodiversity includes a detailed description of the relevance of biodiversity indicators. ${ }^{6}$ In general, all companies are able to disclose detailed information on materiality, impact, strategy and actions plans for conservation of biodiversity. Despite the fact that the GRI considers biodiversity from the perspective of performance indicators, the GRI indicators have been criticized as too broad and too de-contextualised (Moneva et al., 2006). The implication is that biodiversity indicators could be used as reputation risk management exercises, as Bebbington et al. (2008) revealed about general sustainable reporting.

Recently, the United Nations General Assembly declared 2011-2020 as the Decade on Biodiversity, and announced a Strategic Plan for Biodiversity intended to increase academic research in this area in both the natural sciences and the social sciences (UNEP, 2011). The Swedish Ministry of the Environment joined with the UN in the 2010 International Year for Biodiversity that was announced to promote the awareness of biodiversity risks. Most of Sweden's environmental legislation is developed in association with the EU, which in turn cooperates with the UN and other international organizations. The Swedish Environmental Protection Agency (SEPA) works on behalf of the Swedish Government to provide guidance on environmental policy and to ensure compliance with the Swedish Environmental Code and international policies. In January 1999, the modernised and updated Swedish Environmental Code went into effect. This code is based on Swedish environmental laws that have been written to promote Sweden's vision of sustainable development (SEPA, 2009). The Swedish Biodiversity Centre, established in 1994 by the Swedish Government, is a national institution with a mandate to conduct and co-ordinate research, to promote education and to provide information on topics associated with biodiversity. However, publications from the Swedish Biodiversity Centre indicate that no research has yet addressed biodiversity disclosure by companies. In addition, the mandatory biodiversity disclosure requirements for companies in Sweden are very limited (SEPA, 2011). Consequently, biodiversity disclosures are mainly voluntary disclosures.

Many researchers (e.g., Deegan, 2002; Luft Mobus 2005; Owen, 2008: Laine, 2009; Islam and Deegan, 2010) have asked what motivates organizations to voluntarily disclose environmental information. Critics who look at voluntary environmental disclosures suggest that companies may use the promotional spin called green wash to promote a perception of environmental friendliness (e.g., Newton and Harte, 1997). In an extensive review of SER studies that applied legitimacy theory, Deegan (2002) showed that a considerable number of accounting studies use Lindblom's (1994) legitimacy theory framework, which views disclosure as a legitimizing tool. Luft Mobus (2005) showed that Suchman (1995) extended Lindblom's explanation about why managers voluntarily provide social and environmental disclosures by suggesting that different strategies used to manage legitimacy depend on whether a company is trying to gain, maintain or repair legitimacy.

\footnotetext{
${ }^{6}$ For a comprehensive review, see the GRI 3.1 Guidelines, RG pp. 27-29 and IP pp.17-21.
} 
Companies that use SER disclosure may be responding to threats to their legitimacy stemming from their environmental behaviour (e.g., Luft Mobus, 2005; Cho and Patten, 2007; Bebbington et al., 2008; Milne et al., 2009). O'Dwyer (2002) showed managers' prime motivation for adopting sustainability reporting was to enhance their corporate legitimacy. Hopwood (2009) concluded that companies might engage in environmental reporting in order to increase their legitimacy or to promote a different company image. Cho and Patten (2007) and Patten (2002) have argued that, according to legitimacy theory, companies are expected to provide more information because of societal pressure. However, Patten's (2002) review of earlier studies showed that there is a legitimacy gap when more information does not succeed in its intentions. In this legitimacy gap, the SER disclosure has low credibility because the information provided is selective and has no valid source.

In the research this article reports on, a legitimacy theory framework was useful for analysing the quantity and motivation of biodiversity disclosure when different strategies are identifiable.

\section{Research method}

This section explains how the companies for this study were selected and how semi-structured interviews were used to obtain the views of the preparers of accounts of company biodiversity disclosure. Sweden was chosen as research setting because environmental awareness is deeply rooted in Swedish society. Sweden has an advanced economy in which companies have a common environmental tradition.

The market value-weighted OMXS30 index was used to identify companies because this index consists of 30 companies that have, in total, the largest trading volume on the Stockholm Stock Exchange. Traditionally, these companies receive a large share of attention from a broad readership - the general public as well as the capital markets - and disclose information voluntarily that could provide a better understanding of the corporate context of biodiversity disclosure.

In November 2011, the industry breakdown of the OMXS30 index ${ }^{7}$ had nine industry categories (all market-value weighted): from the largest category of Industrials (29.38\%) to the smallest category of Energy (1.92\%). The other categories that were highlighted in the industry breakdown are Financials (23.57\%), Consumer Discretionary (15.03\%), Telecommunication Services (10.79\%), Information Technology (8.85\%), Health Care (4.66\%), Materials (3.75\%) and Consumer Staples (2.05\%).

In order to present their biodiversity risk exposure, OMXS30 companies were classified according to the three $\mathrm{F} \& \mathrm{C}$ risk-level categories (red-zone, amber-zone and green-zone). The F\&C report (2004) contains a comprehensive description as well as cases to illustrate how a methodology was developed to assign the biodiversity risk level for each sector represented on the London Stock Exchange (FTSE). This F\&C methodology was applied to the OMXS30 companies to analyse whether companies that are identified as red-zone, high-risk sector companies provide different biodiversity disclosure as far as quantity and location compared to amber-zone, medium-risk sector companies and to green-zone, lower-risk sector companies.

Insert Table 2 about here

\footnotetext{
${ }^{7}$ The Exchange has the right to change the number of Index Shares and the composition of the OMXS30 index (NASDAQ, 2011).
} 
Table $2^{8}$ shows there is a great variety of biodiversity risk exposure among the OMXS30 companies. There are four companies in the high-risk sector, where biodiversity risks are likely to be significant. Ten companies are in the medium-risk sector, where biodiversity risks may be significant. Fifteen companies are in the lower-risk sector, where biodiversity risks are variable but the significance is unknown.

To gather data from the narratives published by the OMXS30 companies, their websites were examined on biodiversity disclosure. Each website was analysed to see whether the English version provided financial and SER information similar to that in the Swedish version. All companies appear to have translated their Swedish website directly into English, without significant differences in content ${ }^{9}$. Hence, for the examination of biodiversity disclosure, the English versions were used. Each company has a special section on sustainability.

However, due to its voluntary nature, biodiversity disclosure may appear anywhere in corporate communications. Therefore, all website sections were examined, not just the sustainability sections. That process required examination of archives, presentations, and news announcements, as well as company brochures and reports in electronic form. In order to study whether the quantity of biodiversity disclosure had changed over time, five years of annual reports (2006 to 2010) were analysed for all companies. While it is possible to analyse even earlier annual reports, it is impossible to analyse changes in the content of websites if they are not continuously monitored for changes in content. All website content, ${ }^{10}$ annual reports and available SER disclosure were analysed. For a deeper analysis of content and context, the program NVivo was applied in an analysis of contextual information using Word Trees. ${ }^{11}$ A broad definition of biodiversity was applied to capture companies' mention of ecosystems, habitats, ecosystem services, conservation, preservation, restoration and information on species. The codes and themes were established from carefully studying the data in relation to existing literature. The coding used in the analysis was checked and verified by both researchers ${ }^{12}$.

In order to capture companies' reasons for providing biodiversity disclosure, semi-structured interviews were conducted with the companies' Corporate Social Responsibility Directors (CSRDs). A semi-structured interview approach, with open-ended questions, was chosen for this study. This approach allow interviewees to state views on predetermined topics and let the interviewer to raise additional questions for a more detailed account or clarification. There is a large body of literature on standardised versus non-standardised or semi-structured interviews as far as the appropriate method to use for forming questions and obtaining

\footnotetext{
${ }^{8}$ Table 2 shows two peculiarities of the OMXS30 index. Atlas Copco is the only company in this index that has both A shares and B shares among the companies with the largest trading volume. Nokia has its headquarters in Finland, but is listed in Sweden and is included in OMXS30. Therefore, the final sample of this study consists of 29 Swedish companies.

${ }^{9}$ Content analysis using translations into English might be questioned as sentence-for-sentence will not necessarily yield the same volumetric measurement in comparison with the original language.

However, Campbell, Beck and Shrives (2005) showed that English translations can be assumed to be an accurate rendering of the same narrative. Furthermore, Beck, Campbell and Shrives (2010) developed and utilised the CONI research instrument for mixed content analysis, which showed few significant differences in environmental reporting between the two countries.

${ }^{10}$ All 29 websites were downloaded on 14 October 2011 in order to have a fixed reference point and no changes in content during the analysis.

${ }^{11}$ A Word Tree visualizes the context of the examined word; the word is displayed in its "narrow" context of approximately 5 words on either side.

${ }^{12}$ Milne and Adler (1999) explored the reliability of social and environmental disclosures content analysis and showed that training of coders is vital necessary before their coded output could be relied on. This advice has been followed in this study.
} 
answers (e.g., Taylor and Bogdan, 1984; Moser and Kalton, 1985; Mishler, 1986; Denzin and Lincoln, 1994; Hammersley and Atkinson, 1995). For this study the semi-structured interviews started with general questions about the company's SER history and track record before specifically focusing on biodiversity related questions e.g. Why does your company report biodiversity disclosure?; Who is using the reported biodiversity disclosure?; Why does your company make biodiversity disclosure externally available?; How are SER frameworks being important for biodiversity disclosure? How much feedback on biodiversity disclosures does the company receive from stakeholders? How is feedback from stakeholders being reflected in the company's biodiversity disclosure?

This study revealed that 25 out of 29 OMXS30 companies provided information about SER in the 2010 annual reports but only nine of them provided information regarding biodiversity, which is the highest score in the five-year study period. Two of these companies with biodiversity disclosure were unwilling to be interviewed, which reduced the final participant list to seven respondents. ${ }^{13}$ During the interview scheduling, the majority of the respondents said they preferred a telephone interview because of their intense workload. The interviewees spoke uninterrupted without time constrains by the interviewer and each interview was similar in terms of research method. The interviews lasted between 30 to 60 minutes. All interviews were digitally recorded and later transcribed as documents. Quotes from the interviews are used in the following section ${ }^{14}$. Unsuccessful attempts were made to include even those companies that did not disclose current biodiversity information or state their reasons for not disclosing such information. The most common explanation from the respondents was that other companies, which provide biodiversity disclosure, could answer questions about biodiversity disclosure.

\section{Quantity, location and motivation in biodiversity reporting}

This section presents the findings from the disclosure study of corporate information on biodiversity. At first a general overview of the quantity and location of the overall level of SER disclosure is provided. This overview also includes the results on biodiversity disclosure by Swedish companies. The quantity and location of general SER disclosure and specific biodiversity disclosure by the 29 companies were examined over a five-year period (2006 to 2010). Then the focus is on the corporate motivation behind biodiversity disclosure.

Insert Table 3 about here

Table 3 presents the location and quantity of general SER, which includes biodiversity disclosure, without conclusions on the quality of such information. All companies have a SER section on their corporate website. However, the content of the SER websites, in many cases, is identical to the companies' text in their annual reports and/or in their SER disclosure. The website content is dynamic and easily changed. However, AstraZeneca is an example of a company that provides the entire SER web content as a 214 pages report. This report is the longest in the entire sample of company websites. A recent study on integrated reporting by Solomon and Maroun (2012) identified similar reporting of SER content by companies in their corporate reports. The size of annual reports and SER reports has steadily increased in

\footnotetext{
${ }^{13}$ In order to fulfil the ethics requirements of our universities, anonymity was guaranteed to the respondents. Consequently, all quoted remarks from the interviews were carefully edited to prevent identification of individuals, organizations and products. Respondents are referred to as $\mathrm{C} 1, \mathrm{C} 2, \mathrm{C} 3, \mathrm{C} 4$, C5, C6, C7.

${ }^{14}$ Silverman (2012) provides a comprehensive review about interpreting qualitative data and critical reflections necessary by researchers to use quotes.
} 
recent years (e.g., Campbell, 2000; Campbell et al., 2003; KPMG, 2011). This finding is supported by the study because the number of pages for the analysed companies, on average, increased by $25 \%$ in 2010 compared to 2006 .

The mean for the number of annual report pages increased from 111.7 pages in 2006 to 140.0 pages in 2011. It may be noted that the mean of number of SER pages also increased in this time frame from 4.41 pages in 2006 to 6.38 pages in 2011. In 2006, the mean of SER pages in annual reports was 4.41 and increased to 6.38 pages in 2010. In 2010, on average, SER pages were $4.62 \%$ of annual report pages. 21 companies provided stand-alone SER reports in 2010 , which is six more as in 2006 ( 15 companies). The stand-alone SER reports as a percentage annual report pages grew from a mean of 18.97 in 2006 to 434.36 in 2010. In 2010, Nokia Corporation (Nokia) and Hennes \& Mauritz had SER reports that are 18\% and $49 \%$, respectively, larger in volume than their annual reports.

A comparison between companies in the different risk categories green, amber and red in Table 3 shows that the highest mean of SER information in the annual report are from those of the green category, followed by amber and red. In 2010, the average number of pages SER information in the Annual report for category green are 6.8, for the companies in category amber the average are 6.3 pages and for companies in the red category there are an average of 5.0 pages SER information in the annual report. Over the years $2006-2012$ there has been an increase in the average number of pages containing SER information in the annual report, but the relationship between the categories have remained largely the same. In order to detect any potential difference among the three risk categories groups of companies a Kruskal Wallis ${ }^{15}$ test (for the continuous variables) and a Fisher's Exact Probability ${ }^{16}$ Chi-Square test (for the categorical variables) were performed. The results of these tests show that there is no statistically significant difference among the means of the three groups for all the examined variables. This result is contradicting the $\mathrm{F} \& \mathrm{C}$ reports findings, which suggest that there should be differences in biodiversity disclosure between risk categories.

The number of companies in each category that have a standalone SER report for 2010, is $80 \%$ of companies in the green category, $70 \%$ of companies in the amber and $50 \%$ of companies in the red category. An interesting fact is that the amber category in 2010 has a mean of 56.70 pages for their standalone SER reports, which is larger than 40.67 for companies in the green category and 32.75 for companies in the red category. However, the study shows that companies in the green category often have a separate SER report, at the same time they have more pages of SER information in the Annual report.

In 2010, only three companies-Getinge, Investor and Securitas-did not use a SER framework. In 2006, 16 companies did not use a SER framework. Hence, almost all companies in 2010 applied the GRI or referred to UN Global Compact ${ }^{17}$ in order to report their sustainability. The same argument applies for the slowly increasing use of third party assurance, which grew in this study from five companies in 2006 to eleven companies in 2010 External assurance provides stakeholders with more confidence in corporate reporting. Although such assurance is not mandatory for SER reports, recent research (c.f. O'Dwyer, 2011) shows that assurance of SER reports is a growing area whereby companies have the opportunity, although not the necessity, to employ the same auditor that assures their financial accounting reports. There are also specialised companies that can provide assurance of SER

\footnotetext{
${ }^{15}$ A Kruskal - Wallis test is the non-parametric alternative to an ANOVA test. It allows the comparison of scores for more than two groups simultaneously.

${ }^{16}$ The Fisher's Exact Probability Chi-Square test is an independence test similar to Pearson's chi-square but, unlike that, it relaxes the assumption that each cell should have a minimum expected count of five.

${ }^{17}$ In a press release from 28 May 2010, the United Nations Global Compact announced an agreement to align their work with the Global Reporting Initiative (GRI) recommending GRI Guidelines as a reporting framework (UNGC, 2010).
} 
information (Edgley et al., 2010; Jones and Solomon, 2010; O'Dwyer, Owen, and Unerman, 2011). In Sweden, two such companies are Bureau Veritas (BV) and Det Norske Veritas (DNV), both of which specialise in inspections and certifications.

Insert Table 4 about here

In an examination of the quantity and location of biodiversity disclosure, Table 4 shows that less than one-third of the 29 OMXS30 companies in this study report biodiversity information. While 12 companies mention biodiversity throughout the studied period 20062010 , only 9 of them provide biodiversity disclosure in 2010. Atlas Copco, Skanska and Lundin Petroleum mention biodiversity but give no further information that provides context. The overall level of biodiversity reporting is rather low, as nine companies provide biodiversity disclosure, which basically is done as GRI indicators. Except for AstraZeneca and Nokia, the information on biodiversity environmental impact is very general.

An analysis of the companies according to the different risk categories green, amber and red in Table 4 shows that the highest mean (1.0) of biodiversity narrative is to be found in the red category in 2010. However, while a 4 companies do not provide a comprehensive or detailed narrative but just mention biodiversity, the mean for the previous years was 0.25 (equal to 1 company). More interesting is the development over time for biodiversity indicators. Here a continuous trend in increased biodiversity reporting can be obtained, which grew from a 0.07 mean in 2006 to 0.31 in 2010. All categories green, amber and red show the same development. However, only Nokia and ABB have a continuously disclosed biodiversity indicators for four years or more. In order to detect any potential differences among the three risk groups of companies a Fisher's Exact Probability Chi-Square test was performed. The test shows that only the Biodiversity Narratives of 2010 have a significant difference between the three groups. However, these results should not be overstated as the sample is very small and only 9 companies provide biodiversity disclosures.

AstraZeneca is the only company in this study that provides more detailed biodiversity narratives. Thus, it is the leader among the OMXS30 companies in terms of quantity of biodiversity disclosure. AstraZeneca has all its SER information online, including disclosure on biodiversity, which they provide as an electronic document on an annual basis. AstraZeneca is also the only company that reports biodiversity action plans.

"We have confirmed that the majority of these sites have considerable biodiversity value and/or potential. To date, in consultation with local stakeholders and conservation organisations, we have prepared local Biodiversity Action Plans (BAPs) for three of them - two sites in the UK and one in Sweden." (AstraZeneca SER report 2010)

AstraZeneca's biodiversity disclosure is quite detailed and includes a number of examples on actions taken in relation to biodiversity issues. The company also uses GRI indicators. This disclosure effort may be the result of the spill-over effect of its UK origins. As Grabsch et al. (2010) discuss, British companies lead in biodiversity disclosure in comparison with German companies.

However, the majority of the OMXS30 companies do not report detailed information on biodiversity issues. Overall, there does not seem to be a relationship between red-zone sector companies and their propensity for biodiversity disclosure that the $\mathrm{F} \& \mathrm{C}$ report assumes (F\&C, 2004). For example, the mining company, Boliden (a red-zone sector company) reports very generally on its efforts to conserve nature and wildlife. 
"The designation entails a two-pronged approach, leaving some parts of the forest untouched while actively maintaining others, in order to conserve and develop the natural environment and wildlife." (Boliden, SER website 2011)

Frequently, the OMXS30 companies dismiss biodiversity concerns as rather irrelevant since they claim their activities have no negative impact on the environment. Nevertheless, they still make general statements that promote the value of biodiversity protection and conservation.

"ABB's manufacturing and workshop facilities are not located in, or
adjacent to, protected areas or areas of high biodiversity value $[\ldots]$
Nonetheless, ABB works to rehabilitate our own sites and some of
our operations $[\ldots .$.$] in Taiwan focuses on wetland conservation,$
partnering with the Guandu Nature Park and Chouchai Wetland Park.
Both parks are significant habitats and breeding grounds for a wide
variety of bird species and ABB supports the rehabilitation and
maintenance of these valuable sites." (ABB SER report 2010)

Some Swedish companies (e.g., Hennes \& Mauritz) offer very brief biodiversity statements in the context of their company's environmental impact according to the GRI indicators.

"Organic cultivation reduces the potential negative impact of cotton on local water quality and biodiversity." (H\&M SER report 2010)

The GRI guidelines on Biodiversity Reporting highlight that most production processes influence biodiversity, either positively or negatively. Therefore, links can be made between biodiversity and other Environmental Performance Indicators such as Water, Air, Soil and Habitat (GRI, 2011).

Most biodiversity disclosures by OMX30 companies are related to GRI indicators EN11 and EN12, the core indicators about location and impact on protected areas. However, when these indicators are disclosed, companies often mention that their production units are located in industrial areas. This implies that the production units are not located within biodiversity sensitive areas. Statements like the one from ABB are rather common for those companies that are providing biodiversity disclosures. Some of the disclosures are more general statements about biodiversity such as made by Nokia (2010) when they described the world's ecosystem as crucial for all life on Earth, and that Nokia want to take an active role in protecting the variety of life. There are also some statements, e.g. Electrolux in 2010 SER report, that companies' production does not affect nature and biodiversity compared to many other manufacturing industries.

In summary, Table 4 shows that the OMXS30 companies rarely publish biodiversity disclosure information. When they make statements related to biodiversity, these statements seldom reveal in-depth information. Rather, they discuss environmental impact only in a broad context. Nonetheless, Table 4 shows that biodiversity disclosure is increasing. The number of companies in the study that made biodiversity disclosure doubled from 2009 to 2010 .

Patten (2002) found that companies who have a negative environmental impact have an incentive to address threats to their legitimacy. However, no support was found for this result in the biodiversity disclosure of this study. For example, SCA, a producer of forest products, does not comment on the clear-cut logging problem and negative effects on biodiversity 
associated with these problems. Indeed, SCA makes no biodiversity disclosure on this issue.

In order to capture companies' motivations for providing biodiversity information, semistructured interviews with the CSRDs were conducted. Although Table 4 illustrates a low level of biodiversity reporting, these respondents for the companies could provide some information. Therefore, it was asked why their companies report biodiversity. In the interviews, the interviewees offered various reasons.

It seems that companies might have had a general anthropological approach to biodiversity from the beginning, but they admit that they understand and acknowledge the risk component of biodiversity.

"[...] , biodiversity is much more specific than the overall CSR issue as such. [...] our BUSINESS is probably having a greater impact than other businesses. Therefore, we have to ensure that we do everything to prevent harm to the ecosystem [...]." (Quote from C1)

Consequently, the financially-related aspect of biodiversity management seem to facilitate the companies' interest in biodiversity in order to reduce potential future costs and liabilities, which arises from companies' impact of their production on biodiversity. This is in line with the F\&C report (2004), which addresses that biodiversity risks have to be identified and tackled in its early stages in order to affect the long-term outcome of the company. Companies have to foresee emerging challenges such as the trend of biodiversity disclosure, e.g. as stated by respondent $\mathrm{C} 2$.

"Two years ago this had certainly not been on our task list. Biodiversity reporting is considering indicators like impact on local wildlife, etc. [...] I can tell you, if you are not taking up this new challenge, the media will give you a hard time [...]." (Quote from C2)

Taking the developments in Table 3 and Table 4 into consideration, biodiversity seems to be a rather recent challenge to these companies. As noted above, while the general level of biodiversity disclosure is low, the number of companies providing biodiversity disclosure doubled between 2006 and 2010. However, it seems that companies start to acknowledge the critical relationship between risk and biodiversity.

"After the INCIDENT, we had to start working on biodiversity reporting. For some pressure groups it might be a reason to divest. That's not good because you have to work hard for your reputation. [...]" (Quote from C3)

The motivations for biodiversity disclosure that the respondents gave correspond to Suchman's (1995) strategies of gaining (see C1 quote), maintaining (see C2 quote) and repairing legitimacy (see $\mathrm{C} 3$ quote). In the interviews, many respondents made statements about the necessity of responding to future changes in order to protect their companies' good reputations that had been acquired over many years.

Grabsch et al. (2010) describe biodiversity disclosure via corporate sustainable reports as a way to demonstrate care for stakeholders. The respondents explained that their companies have responsibilities to different stakeholder groups: the general public, the shareholders and the employees. As part of the investigation into biodiversity disclosure motivations, it was interesting to learn why companies report biodiversity externally. The respondents offered the following reasons. 
"Once you have implemented a measurement system internally you can easily use this data externally. If it is biodiversity data or other financial data, it makes no difference in this case. Once you have the data you can provide it if you think it's something for shareholders." (Quote from C1)

Burritt and Schaltegger (2010) showed that sustainability reporting is a result of pressures from internal, external parties and from opportunities. It seems to be shown in the interviews that biodiversity disclosures stem from internal pressures and opportunities but not so much as pressure from external party.

"We experienced that society currently is going towards more information on the environment. [...] What we did at COMPANY was that we took our engineers and looked into all ingredients that PRODUCT needs. If they could lead to contamination [...] Of course, this you can tell in your environmental reports." (Quote from C5)

This is more an inside-out approach to biodiversity disclosure. Burritt and Schaltegger (2010) described the inside-out approach as being a pragmatic approach that transforms strategically related sustainability topics into key performance indicators and information sets.

“[...] our employees are the most important stakeholders in the development of improving our sustainability. It is one thing to put it into our reports. Of course, other people might read it as well [...]” (Quote from C7)

Therefore, biodiversity disclosure that is developed for satisfying the information needs internally can also become externalised and made available to external stakeholders.

The biodiversity disclosure analysis showed that almost all the OMXS30 companies that made biodiversity disclosure applied a SER framework. Therefore, inquires have been directed towards the importance of reporting frameworks for SER and especially for biodiversity disclosure.

"We started to introduce GRI some years ago [...] until then we managed this more or less on our own. [...] It's not really a cook book but gives you a hint of what to disclose." (Quote from C2)

In addition to the recent research on stand-alone SER reports' content, there is also research on the role of reporting frameworks such as the GRI (e.g., Laine, 2005; Moneva et al., 2006; Tregidga and Milne, 2006). The interviewees made specific comments regarding the role of reporting frameworks.

"[...] my colleagues got involved in this project when they started with GRI. [...] I am glad that this had been done before I came. [...] It's a hell of a job. Now, we have our EMS that helps us to report all info we need for ISO and the GRI indicators. [...] Basically, we started to consider biodiversity when we felt the need to increase our info about our sustainability. GRI is a facilitator in this case [...].” (Quote from C4)

The respondents singled out the GRI reporting framework as a facilitator for SER reporting. The technical protocols and guidance are regarded to enhance the reporting of specific areas of interest such as biodiversity disclosure, which develops over time.

"We were not among the leaders in this issue. We looked at what COMPANY and COMPANY had. [...] It's good to be comparable. They had GRI. [...] We slowly advanced in which GRI indicators to provide. [...] As you can see, we 
partially applied biodiversity indicators [...]. However, guidance and technical protocols are quite helpful in improving our reporting. Still this issue is becoming an increased concern, and therefore we would like to act as a good citizen [...]." (Quote from C5)

That the interviewees mentioned GRI as a facilitator for biodiversity disclosure is in line with previous research. Brown et al. (2009) illustrate GRI's general role as the best-known sustainability reporting framework that companies will follow and adopt to enhance their growing reporting scope and depth, which includes biodiversity disclosure. Burritt and Schaltegger (2010) described GRI as an outside-in approach to sustainability reporting where key performance indicators are provided externally and is only marginally influenced by the needs internally. Furthermore, GRI can be reviewed as institutional entrepreneur that introduces companies to a set of key performance indicators that can be applied. The results from the interviews illustrate that this might be the case for biodiversity disclosure.

Stakeholder theory suggests that companies will manage these relationships once feedback has been provided. Stakeholders can provide feedback to companies on their SER reports and biodiversity disclosure. Therefore, respondents were asked to outline if and how such stakeholder feedback could be reflected in company SER reports. However, the respondents' view of biodiversity disclosure does not seem to align with previous research on the relationship between external pressure groups and SER disclosure (e.g., Campbell et al., 2003; de Villiers and van Staden, 2010).

"Due to the INCIDENT we were approached by NGOs like Greenpeace [...] in another case we were contacted by SSNC about PRODUCT usage. That was regarding biodiversity, as we had a problem with our factory and toxic spill water [...]. However, I would not say that this has changed how we report" (Quote from C1)

"[...] environmentalists, activists and NGOs rarely provide direct feedback on the information we provide. [...] We use our reports when we are working with improving environmental issues at our factories [...] Here you can get direct feedback." (Quote from C6)

The interviews give the impression that the companies have a rather vague idea about the identity of the users of this information. It seems that companies in this study are not responding to all stakeholders equally as they seem to neglect external stakeholders while they prefer to satisfy the disclosure needs on biodiversity from stakeholders within the company. The overall impression on biodiversity disclosure in this study illustrates a rather positive picture of the companies when it comes to the protection and preservation of biodiversity. Only a small number of companies do provide some details on biodiversity but consequences from incidents that might had a negative impact on biodiversity are absent.

\section{Concluding discussion}

The principal purpose of this article is to provide an analysis of the quantity, location and intentions behind biodiversity reporting. For the quantity and location research, 29 companies' corporate websites and various reports, including annual reports, were analysed. The companies were chosen from the OMXS30 index on the Stockholm Stock Exchange. The analysis focused on biodiversity disclosure.

Considerable attention has been paid to the content of social and environmental reports in recent years (e.g., Hackston and Milne, 1996; Campbell et al., 2003; Laine, 2005; Moneva et al., 2006; Tregidga and Milne, 2006). However, the research that focuses specifically on 
biodiversity is currently very limited (e.g., Jones 1996, 2003; Jones and Matthews, 2000; Houdet, 2008; Houdet et al., 2009; Garbsch et al., 2010). By studying the Swedish context of biodiversity disclosure, this article informs the debate on capturing the status quo of biodiversity risk reporting in a country that is among the leading countries in such reporting (KPMG, 2011).

The article contributes to this emerging area of social and environmental accounting by combining an explorative and descriptive analysis of companies' biodiversity disclosure with interview data from preparers of such disclosure. The examination of the content of corporate reports (SER reports in general and biodiversity disclosure in particular) over a five-year period permitted tracing the development of these reporting practices.

This study, which analysed 29 OMXS30 companies' websites and corporate reports, presents a broad overview of the quantity and location of social and environmental reporting practices in a Swedish setting. A basic problem with corporate websites is content-related. This problem is, to some extent, attributable to its dynamic nature; website content is easy to change without leaving traces if deleted. The content-related problem is more a weakness of corporate information content as the texts, in many instances, repeat identical information regardless of location (e.g., websites, annual reports or sustainability reports).

AstraZeneca provides a prime example of this content-repeating behaviour. The company informs its users that its electronic SER report is a document that reports the entire website SER content. Similar practices among other companies were found in this study with respect to the location of the recycled information (e.g., websites and SER reports). Among companies elsewhere, AstraZeneca is far from an exception. Solomon and Maroun (2012) found similar behaviour at South African companies in their analysis of integrated reporting. They conclude that companies try to make the most from a small amount of information. However, the practice may not present a problem so as long as the information is available and retrievable.

Earlier studies assume that environmental awareness has changed over time and that companies may respond to this situation by increasing their information disclosure (Deegan and Gordon, 1996). Our five-year analysis involved counting the number of pages in annual reports and SER reports. It is possible that such a calculation is a somewhat crude measure. However, page proportion count still allows a longitudinal analysis of the general disclosure level, as earlier studies have shown (e.g., Gray et al., 1995; Campbell, 2000). The results from this study show that the number of pages for the OMXS30 companies increased by $25 \%$ from 2006 to 2010. The number of pages on SER in annual reports grew by the same amount and has remained more or less at the same level. In 2010, the SER pages are $4.62 \%$ of the annual report pages. One conclusion is that environmental awareness may have reached the same level during the past five years. However, a closer look at the number of pages in the SER stand-alone reports shows that there has been an increase of $269 \%$ in the past five years. This finding is consistent with other studies that count the number of words in corporate social disclosures (Campbell et al., 2003).

Despite the increasing number of SER report pages, this study shows that only a few companies provide biodiversity information in any significant quantity. When provided, that information is quite limited and rather general. As far as location, biodiversity disclosure does not always appear in the sustainability sections of the corporate websites but rather in the SER reports and/or the annual reports. Except for ABB, AstraZeneca and Nokia, the biodiversity disclosure by the OMXS30 companies consists of general narratives. AstraZeneca provides a biodiversity narrative that describes its biodiversity action plans and performance information on the GRI index. ABB and Nokia, which are less detailed in their biodiversity narratives, present a more general survey. An interesting fact is that SCA provides general biodiversity 
narratives for the three latest years of the study, but does not mention the formal complaint SSNC and Greenpeace made to the FSC.

This longitudinal study of biodiversity disclosure illustrates that the subject is a rather recent disclosure issue for OMXS30 companies. In 2010, nine of 29 analysed companies reported biodiversity information whereas only four companies reported biodiversity information in 2009. ABB is the only company that has included biodiversity indicators in its SER reports each year in the five-year study period.

It is evident from this study that the volume of SER disclosure in general, as well as biodiversity disclosure in particular, varies among companies. However, the statistical tests show that these differences are not related to risk sectors, as suggested by the F\&C report (F\&C, 2004). The general assumption from previous research (e.g., Gray et al., 1995; Deegan and Gordon, 1996; Campbell, 2000, Patten, 2002; Cho and Patten, 2007) is that companies that tend to experience stronger group pressure respond to this pressure by disclosing more information using different legitimising tools. However, the study does not confirm this assumption, as the statistical tests basically showed insignificant results. For example, ABB and Nokia, which are green-zone risk sector companies, present much more biodiversity disclosure and SER reporting than the red-zone risk sector company, SCA. Moreover, neither the red-zone risk sector companies nor the green-zone risk sector companies disclose more detailed information on biodiversity or SER. Consequently, this study challenges the F\&C classification for determining companies' biodiversity risk profiles. In general, very few companies refer to biodiversity in terms of risks, including financial risk. Therefore, legitimacy theory does not necessarily correspond with the quantity of biodiversity disclosure.

Despite the intentions behind biodiversity disclosure that the respondents gave in the interviews - some of which correspond to Suchman's (1995) strategies of gaining, maintaining and repairing legitimacy - it is difficult to verify them by the quantity of disclosure noted in this study. Some OMXS30 companies have increased their SER disclosure in order to repair or gain legitimacy. However, considering the $25 \%$ increase in the volume of the annual reports and the $269 \%$ increase in the volume of stand-alone SER reports, it is somewhat controversial to assume that all companies need to close a large legitimacy gap. As Campbell et al. (2003) conclude increased SER disclosure is not necessarily proof of legitimacy.

Interviews and SER reports indicate that disclosure itself is a challenge that companies face as disclosure simultaneously can be a response to challenges that companies are confronted with. Some interviews in this study showed that strategies are applied that changed reporting according to stakeholder needs. This supports that actions might be taken to redress an issue a company is facing in order to show proof of legitimacy.

The use of SER frameworks and guidelines as catalysts for biodiversity disclosure is of interest. Milne et al. (2009) state that the emergence and development of the GRI Guidelines provide an entity-focused view of sustainable development that enables companies to "do" sustainable development by integrating it into their business practices. In the interviews, respondents identified the GRI reporting framework, with its performance indicators, as a facilitator of biodiversity disclosure. It may also be that the absence of pressure and feedback from outside groups and stakeholders is a factor. The respondents state they have little interaction with such groups and stakeholders.

In summary, the findings from the interviews show that biodiversity disclosure is a very new issue for OMXS30 companies. Because of its newness, it appears these companies have not developed a clear strategy for providing biodiversity disclosure in their external reports. This might also explain why there was no statistical significance in the biodiversity disclosure between different risk categories, which could have been according to prior literature. 
Moreover, biodiversity disclosure has not evolved from internal environment management systems. Instead, as the interviews reveal, companies provide biodiversity disclosure primarily because the use of SER reports and the application of the GRI Framework have facilitated the production and publication of such information.

There are some limitations to this study. It may be that this study is somewhat premature in its analysis of in-depth biodiversity disclosure practices. This study shows that, as of 2010, very few OMXS30 companies disclosed biodiversity information even though the number of such companies making such disclosures has doubled since 2009. Although the data provide no clear explanation for this doubling, it still appears that biodiversity disclosure is in its early stages. Possibly some OMXS30 companies (e.g., Volvo and SKF) have just begun to rethink their entire approach to SER reporting following the integrated reporting on social, environmental and ethical issues in their annual reports. Such companies may now be adopting biodiversity disclosure as well.

Future research on biodiversity disclosure could take a different approach than the existing studies, this research included, by studying the process of biodiversity disclosure at companies. Currently, no study exists on how companies work with biodiversity disclosure. Some respondents indicated in the interviews that information for SER disclosure might be difficult to collect within the companies because their environmental management systems are quite different from their accounting information systems. This difference may be another explanation for the low level of biodiversity disclosure.

\section{References}

Adams, C. A. (2004), "The ethical, social and environmental reporting performance portrayal gap”, Accounting, Auditing and Accountability Journal, Vol. 17 No. 5, pp. 731-757.

Adams, C. A. (2008), "A commentary on: Corporate social responsibility reporting and reputation risk management", Accounting, Auditing and Accountability Journal, Vol. 21 No. 3, pp. 365-370.

Adams, C. A. and Larrinaga-González, C. (2007), "Engaging with organisations in pursuit of improved sustainability accounting and performance", Accounting, Auditing \& Accountability Journal, Vol. 20 No 3, pp. 333-355.

Archel, P., Husillos, J., Larrinaga C. and Spence, C. (2009), "Social disclosure, legitimacy theory and the role of the state", Accounting, Auditing \& Accountability Journal, Vol. 22 No. 8, pp. 1284-1307.

Beck, A. C., Campbell, D. and Shrives, P. J. (2010), "Content analysis in environmental reporting research: Enrichment and rehearsal of the method in a British-German context", The British Accounting Review, Vol. 42 No. 3, pp. 207-222.

Bebbington, J., Larrinaga-González, C. and Moneva, J. M. (2008), "Legitimating reputation/the reputation of legitimacy theory", Accounting, Auditing \& Accountability Journal, Vol. 21 No 3, pp. 371-374.

Brown, H.S., de Jong, M. and Lessidrenska, T. (2009), "The rise of the global reporting initiative: a case of institutional entrepreneurship", Environmental Politics, Vol. 18 No. 2, pp. 182-200.

Burritt, R. L. and Schaltegger, S. (2010), "Sustainability accounting and reporting: Fad or trend?" Accounting, Auditing \& Accountability Journal, Vol. 23 No 7, pp. 829-846. 
Campbell, D. (2000), "Legitimacy theory or managerial reality construction. Corporate social disclosures in Marks \& Spencer corporate reports", Accounting Forum, Vol. 24 No. 1, pp. 80-100.

Campbell, D., Craven, B. and Shrives, P. (2003), "Voluntary social reporting in three FTSE sectors: A comment on perception and legitimacy", Accounting, Auditing \& Accountability Journal, Vol. 16 No. 4, pp. 558-581.

Campbell, D., Beck, A. C. and Shrives, P. J. (2005), "A note on comparative language interrogation for content analysis: The example of English vs. German", The British Accounting Review, Vol. 37 No. 4, pp. 339-350.

CBD (1992), Convention on Biological Diversity, United Nations, pp. 1-30.

Cho, C. and Patten, D. M. (2007), "The role of environmental disclosure as legitimacy tools: A research note", Accounting Organizations and Society, Vol. 32 No. 7, pp. 639-647.

De Villiers, C. and Van Staden, C. J. (2010), "Shareholders' requirements for corporate environmental disclosures: A cross country comparison", The British Accounting Review, Vol. 42 No. 4, pp. 227-240.

Deegan, C. (2002), "Introduction: The legitimising effect of social and environmental disclosures - a theoretical foundation", Accounting, Auditing \& Accountability Journal, Vol. 15 No. 3, pp. 282-311.

Deegan, C. And Gordon, B. (1996), "A study of the environmental disclosur policies of Australian corporations", Accounting and Business Research, Vol. 26 No. 3, pp. 187199.

Denzin, N. K. and Lincoln, Y. S. (1994), "Introduction: entering the field of qualitative research", in Denzin, N. K. and Lincoln, Y. (Eds.) Handbook of Qualitative Research, Sage Publications Inc., Thousand Oaks, CA, pp. 1-17.

Dowling, J., and Pfeffer, J. (1975), "Organizational legitimacy: Social values and organizational behaviour", Pacific Sociological Review, Vol. 18, pp. 122-136.

Edgley, C. R., Jones, M. J. and Solomon, J. F. (2010) "Stakeholder inclusivity in social and environmental report assurance", Accounting, Auditing \& Accountability Journal, Vol.23 No.4, pp. 532-557.

European Environment Agency (2010), Ecosystem accounting and the cost of biodiversity losses: The case of coastal Mediterranean wetlands, European Environment Agency, Copenhagen, Denmark.

Farneti, F. and Guthrie, J. (2009), "Sustainability reporting by Australian public sector organizations: Why they report", Accounting Forum, Vol. 33 No. 2, pp. 89-98.

F\&C Asset Management plc (2004), Is biodiversity a material risk for companies? An assessment of the exposure of FTSE sectors to biodiversity risk, September, F\&C Asset Management plc, London, UK.

Grabsch, C., Jones, M. J. and Solomon, J. (2010), "Accounting for biodiversity in crisis: A European Perspective", Working paper presented at the $14^{\text {th }}$ Financial Reporting \& Business Communications Conference, Bristol, UK.

Gray, R. H. (2010), "Is accounting for sustainability actually accounting for sustainability ... and how would we know? An exploration of narratives of organisations and the planet", Accounting, Organizations and Society, Vol. 35 No.1, pp. 47-62.

Gray, R., Bebbington, J. and Walters, D. (1993), Accounting for the environment, Paul Chapman Publishing, London, UK. 
Gray, R., Kouhy, R. and Lavers, S. (1995), "Corporate social and environmental reporting: A review of the literature and a longitudinal study of UK disclosure", Accounting, Auditing \& Accountability Journal, Vol. 8, No. 2, pp. 47-77.

Gray, R. H., Owen, D. J. and Maunders, K. T. (1998), "Corporate social reporting: Emerging trends in accountability and the social contract", Accounting, Organizations and Society, Vol. 1 No. 1, pp. 6-20.

GRI (2011), "GRI's G3.1 Sustainability Reporting Guidelines inclusive Technical Protocol”, available at: http://www.globalreporting.org/NR/rdonlyres/7DB67FFF-81EE-402FA218-36940C883DD5/0/G31GuidelinesinclTechnicalProtocolFinal.pdf (accessed 30 September 2011).

Hackston, D. and Milne, M. J. (1996), "Some determinants of social and environmental disclosures in New Zealand companies", Accounting, Auditing \& Accountability Journal, Vol. 9 No. 1, pp. 77-108.

Hammersley, M. and Atkinson, P. (1995) Ethnography - principles in practice, 2nd Ed., Routledge, London, UK.

Henri J.-F. and Journeault, M. (2010), "Eco-control: the influence of management control systems on environmental and economic performance", Accounting, Organizations and Society, Vol. 35 No.1, pp. 63-80.

Hopwood, A. G. (2009), "Accounting and the environment", Accounting, Organizations and Society, Vol. 34 No. 8, pp. 433-439.

Houdet, J. (2008), Integrating biodiversity into business strategies. The Biodiversity Accountability Framework. FRB-Orée, Paris.

Houdet, J. Pavageau, C., Trommetter, M. and Weber, J. (2009), “Accounting for changes in biodiversity and ecosystem services from a business perspective: Preliminary guidelines towards a biodiversity accountability framework", Working paper, Ecole Polytechnique, available at: http://www.oree.org/_script/ntsp-documentfile_download.php?document_file_id=133 (accessed 5 October 2011).

Islam, M. A. and Deegan, C. (2010), "Media pressures and corporate disclosure of social responsibility performance information: A study of two global clothing and sports retail companies", Accounting \& Business Research, Vol. 40 No. 2, pp. 131-148.

Jones, M. J. (1996) “Accounting for biodiversity: A pilot study", British Accounting Review, Vol. 28, pp. 281-303.

Jones, M. J. (2003) "Accounting for biodiversity: operationalist environmental accounting", Accounting, Auditing and Accountability Journal, Vol. 16 No. 5, pp. 762-789.

Jones, M. J. and Matthews, R. (2000), Accounting for biodiversity - A natural inventory of the Elan Valley Nature Reserve, ACCA Occasional Research Paper No.29, ACCA, London, UK.

Jones, M. J and Solomon, J. F. (2010) "Social and environmental report assurance: some interview evidence", Accounting Forum, Vol. 34 No.1, March, pp. 20-31.

KPMG (2011), International survey of corporate responsibility reporting, available at www.kpmg.com, (accessed 1 December 2011).

Laine, M. (2005), "Meanings of the term "sustainable development in Finnish corporate disclosures", Accounting Forum, Vol. 29 No. 4, pp. 395-413.

Laine, M. (2009), "Ensuring legitimacy through rhetorical changes? A longitudinal interpretation of the environmental disclosures of a leading Finnish chemical company", Accounting, Auditing \& Accountability Journal, Vol. 22 No. 7, pp.10291054. 
Larrinaga-González, C. and Bebbington, J. (2001), “Accounting change or institutional appropriation? A case study of the implementation of environmental accounting", Critical Perspectives on Accounting, Vol. 12 No.3, pp. 269-292.

Lindblom, C. K. (1994), "The implications of organizational legitimacy for corporate social performance and disclosure", Critical Perspectives on Accounting Conference, New York.

Luft Mobus, J. (2005), "Mandatory environmental disclosures in a legitimacy theory context", Accounting, Auditing \& Accountability Journal, Vol. 18 No. 4, pp. 492-517.

Millennium Ecosystem Assessment (2005), Ecosystems and human well-being: Current state and trends, Volume 1, Island Press, Washington, USA.

Milne, M. J. (1991), "Accounting, environmental resource values and non-market valuation techniques for environmental resources: A review", Accounting, Auditing \& Accountability Journal, Vol. 4 No 3, pp. 81-109.

Milne, M.J., (1996), "On sustainability, the environment and management accounting", Management Accounting Research, Vol. 7 No. 1, pp. 135-161.

Milne, M. J. and Adler, R. W. (1999), "Exploring the reliability of social and environmental disclosures content analysis", Accounting, Auditing \& Accountability Journal, Vol. 12 No. 2, pp. 237-256.

Milne, M. J. and Gray, R. H. (2007), "Future prospects for corporate sustainability reporting", in Unerman, J., Bebbington, J. and O'Dwyer, B. (eds.) Sustainability Accounting and Accountability, pp.184-208, Routledge, London, UK.

Milne, M. J., Tregidga, H. and Walton, S. (2009), "Words not actions! The ideological role of sustainable development reporting", Accounting, Auditing \& Accountability Journal, Vol. 22 No. 8, pp. 1211-1257.

Mishler, E. G. (1986), Research Interviewing, Harvard University Press, London, UK.

Moneva, J. M., Archel, P. and Correa, C., (2006), "GRI and the camouflaging of corporate unsustainability", Accounting Forum, Vol. 30 No.2, pp. 121-137.

Moser, S. C. and Kalton, G. (1985), Survey methods in social investigation, Gower Publishing Company, Hants, UK.

NASDAQ (2011), OMXS30 index methodology, available at https://indexes.nasdaqomx.com/data.aspx?IndexSymbol=OMXS30, (accessed 16 September 2011).

Newton, T. and Harte, G. (1997), "Green business: Technicist kitsch?", Journal of Management Studies, Vol. 34 No.1, pp. 75-98.

O'Dwyer, B. (2002), "Conceptions of corporate social responsibility: The nature of managerial capture", Accounting, Auditing \& Accountability Journal, Vol. 16, No. 4, pp. 523-557.

O'Dwyer, B. (2011), "The Case of Sustainability Assurance: constructing a new assurance service", Contemporary Accounting Research, Vol. 28 No. 4, pp. 1230-1266

O'Dwyer, B., Owen, D. L. and Unerman, J. (2011), "Seeking legitimacy for new assurance forms: The case of sustainability assurance", Accounting, Organizations and Society, Vol. 36 No. 1, pp. 31-52.

Owen, D. (2008), "Chronicles of wasted time? A personal reflection on the current state of, and future prospects for, social and environmental accounting research", Accounting, Auditing \& Accountability Journal, Vol. 21 No. 2, pp. 240-267. 
Patten, D. M. (2002), "The relation between environmental performance and environmental disclosure: A research note", Accounting, Organizations and Society, Vol. 27 No. 8, pp. 763-773.

SCB (2009), Statistics Sweden. Befolkning på öar [Population on islands], available at http://www.scb.se/statistik/MI/MI0812/2008A01/MI0812_2008A01_SM_MI50SM0 901.pdf, (accessed: 19 October 2011).

SEPA (2009), Welcome to the Swedish Environmental Protection Agency, SEPA, Stockholm.

SEPA (2011), "The Swedish Environmental Protection Agency", available at http://www.naturvardsverket.se/en/ (accessed 9 November 2011).

Silverman, D. (2012), Interpreting Qualitative Data $-4^{\text {th }}$ edition, SAGE Publications Ltd, London.

Solomon, J. and Maroun, W. (2012), Integrated reporting: The influence of King III on social, ethical and environmental reporting, ACCA, London.

SSIC (2010), Rödlistade arter i Sverige 2010 - The 2010 red-list of Swedish species, Swedish Species Information Centre, Uppsala.

SSNC (2010), Cutting the edge - the loss of natural forests in Sweden, Swedish Society for Nature Conservation Report, Stockholm.

SSNC (2011), Under the cover of the Swedish forestry model, Swedish Society for Nature Conservation Report, Stockholm.

Suchman, M. (1995), "Managing legitimacy: Strategic and institutional approaches", The Academy of Management Review, Vol. 20 No. 3, pp. 571-610.

Taylor, S. J. and Bogdan, R. (1984), Introduction to qualitative research methods: The search for meanings, 2nd Ed., John Wiley \& Sons, Inc., New York.

TEEB (2008), "Economics of ecosystems and biodiversity report", available at: www.teeb.org (accessed 30 September 2011).

Thomson, I. (2007), "Mapping the terrain of sustainability accounting", in Unerman, J. Bebbington, J. and O'Dwyer, B. (Eds.), Sustainability accounting and accountability, pp. 19-36., Routledge, London.

Tregidga, H. and Milne, M. J. (2006), "From sustainable management to sustainable development: A longitudinal analysis of a leading New Zealand environmental reporter", Business Strategy and the Environment, Vol. 15 No. 4, pp. 219-241.

UNEP (2011). Keeping track of our changing environment: from Rio to Rio+20 (19922012), Division of Early Warning and Assessment (DEWA), United Nations Environment Programme (UNEP), Nairobi, Kenya.

Unerman, J. (2008), "Strategic reputation risk management and corporate social responsibility reporting", Accounting, Auditing \& Accountability Journal, Vol. 21 No. 3, pp. 362-364.

UNESCO (2010), "List of World Heritage Sites", available at http://whc.unesco.org/en/list (accessed 3 October 2011).

UNGC (2010), "UN Global Compact and Global Reporting Initiative Announce New Collaboration", available at: http://www.unglobalcompact.org/news/34-05-28-2010 (accessed: 23 December 2012).

Waldman, M. and Shevah, Y. (2000), "Biological diversity - an overview", Water, Air, and Soil Pollution, Vol. 123 No. 1-4, pp. 299-310. 
Wilkinson C. (Ed.) (2004), Status of coral reefs of the world: 2004. Australian Institute of Marine Science, Townsville, Australia. 
Table 1

Global Reporting Initiative standard performance disclosure for Biodiversity

\begin{tabular}{|c|c|c|c|}
\hline GRI Aspect & Type & Indicator & Description \\
\hline Biodiversity & Core & EN11 & $\begin{array}{l}\text { Location and size of land owned, leased, managed in, or adjacent to, protected areas and } \\
\text { areas of high biodiversity value outside protected areas. }\end{array}$ \\
\hline Biodiversity & Core & EN12 & $\begin{array}{l}\text { Description of significant impacts of activities, products, and services on biodiversity in } \\
\text { protected areas and areas of high biodiversity value outside protected areas. }\end{array}$ \\
\hline Biodiversity & Additional & EN13 & Habitats protected or restored. \\
\hline Biodiversity & Additional & EN14* content introduced in G3.1 update & Strategies, current actions, and future plans for managing impacts on biodiversity. \\
\hline Biodiversity & Additional & EN15 & $\begin{array}{l}\text { Number of IUCN Red List species and national conservation list species with habitats in } \\
\text { areas affected by operations, by level of extinction risk. }\end{array}$ \\
\hline $\begin{array}{l}\text { Emissions, } \\
\text { Effluents, and } \\
\text { Waste }\end{array}$ & Additional & EN25 & $\begin{array}{l}\text { Identity, size, protected status, and biodiversity value of water bodies and related habitats } \\
\text { significantly affected by the reporting organization's discharges of water and runoff. }\end{array}$ \\
\hline
\end{tabular}


Table 2

OMXS30 categorised by F\&C risk level and ranked by Market Cap

\begin{tabular}{|c|c|c|c|c|c|}
\hline Company & GICS Sector & $\begin{array}{l}\text { F\&C } \\
\text { zone }\end{array}$ & F\&C risk level & $\begin{array}{l}\text { Market Cap } \\
\text { (bn SEK) }\end{array}$ & $\begin{array}{c}\text { Index } \\
\text { weight } \%\end{array}$ \\
\hline Hennes \& Mauritz AB, H \& M ser. B & Consumer discretionary, Apparel Retail & amber & Medium-risk sector & 311 & $11,17 \%$ \\
\hline Nordea Bank AB & Financials, Diversified Banks & amber & Medium-risk sector & 234 & $0,20 \%$ \\
\hline Ericsson, Telefonab. L M ser. B & Information Technology, Communications Equipment & green & Lower-risk sector & 212 & $8,03 \%$ \\
\hline TeliaSonera AB & Telecommunication Services, Integrated Telecommunication Services & green & Lower-risk sector & 195 & $8,17 \%$ \\
\hline Atlas Copco AB ser. $A^{*}$ & Industrials, Industrial Machinery & green & Lower-risk sector & 170 & $4,74 \%$ \\
\hline Nokia Corporation & Telecommunication Services, Communications Equipment & green & Lower-risk sector & 168 & $10,09 \%$ \\
\hline Volvo, AB ser. B & Industrials, Construction \& Farm Machinery \& Heavy Trucks & green & Lower-risk sector & 120 & $5,87 \%$ \\
\hline Svenska Handelsbanken ser. A & Financials, Diversified Banks & amber & Medium-risk sector & 112 & $0,93 \%$ \\
\hline Sandvik AB & Industrials, Industrial Machinery & green & Lower-risk sector & 106 & $5,31 \%$ \\
\hline Skandinaviska Enskilda Banken ser. A & Financials, Diversified Banks & amber & Medium-risk sector & 89 & $4,16 \%$ \\
\hline Swedbank $A B$ ser $A$ & Financials, Diversified Banks & amber & Medium-risk sector & 89 & $3,05 \%$ \\
\hline PLC & Health Care, Pharmaceuticals & amber & Medium-risk sector & 68 & $4,86 \%$ \\
\hline ABB Ltd & Industrials, Heavy Electrical Equipment & green & Lower-risk sector & 65 & $3,02 \%$ \\
\hline SKF, AB ser. B & Industrials, Industrial Machinery & green & Lower-risk sector & 60 & $4,49 \%$ \\
\hline Svenska Cellulosa AB SCA ser. B & Material, Paper Products & red & High-risk sector & 60 & $2,68 \%$ \\
\hline Investor $A B$ ser. $B$ & Financials, Multi-Sector Holdings & amber & Medium-risk sector & 59 & $2,24 \%$ \\
\hline Tele2 AB ser. B & Telecommunication Services, Integrated Telecommunication Services & green & Lower-risk sector & 57 & $2,01 \%$ \\
\hline ASSA ABLOY AB ser. B & Industrials, Building Products & green & Lower-risk sector & 57 & $2,24 \%$ \\
\hline Lundin Petroleum AB & Energy, Oil \& Gas Exploration \& Production & red & High-risk sector & 56 & $0,91 \%$ \\
\hline Alfa Laval AB & Industrials, Industrial Machinery & green & Lower-risk sector & 52 & $2,04 \%$ \\
\hline Swedish Match AB & Consumer Staples, Tobacco & amber & Medium-risk sector & 46 & $1,54 \%$ \\
\hline SCANIA AB ser. B & Industrials, Construction \& Farm Machinery \& Heavy Trucks & green & Lower-risk sector & 44 & $2,19 \%$ \\
\hline Skanska AB ser. B & Industrials, Construction \& Engineering & red & High-risk sector & 42 & $0,93 \%$ \\
\hline Getinge $A B$ ser. $B$ & Health Care, Health Care Equipment & amber & Medium-risk sector & 38 & $1,07 \%$ \\
\hline Electrolux, AB ser. B & Consumer discretionary, Household Appliances & amber & Medium-risk sector & 37 & $1,95 \%$ \\
\hline Boliden AB & Materials, Diversified Metals \& Mining & red & High-risk sector & 26 & $1,28 \%$ \\
\hline Modern Times Group MTG AB ser. B & Consumer discretionary, Broadcasting & green & Lower-risk sector & 21 & $0,91 \%$ \\
\hline Securitas AB ser. B & Industrials, Security \& Alarm Services & green & Lower-risk sector & 20 & $2,11 \%$ \\
\hline SSAB AB ser. A & Materials, Steel & green & Lower-risk sector & 15 & $1,82 \%$ \\
\hline
\end{tabular}




\section{Table 3 Quantity and location of SER disclosure}

\begin{tabular}{|c|c|c|c|c|c|c|c|c|c|c|c|c|c|c|c|c|c|c|c|c|c|c|c|c|c|c|c|c|c|c|c|c|c|c|c|c|c|c|}
\hline Company & $\begin{array}{l}\text { bidivivi riskis } \\
\text { zonen }\end{array}$ & \begin{tabular}{|l} 
SER \\
contact \\
\end{tabular} & \begin{tabular}{|l|} 
SER \\
website
\end{tabular} & 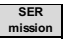 & 2010 & 2009 & $\begin{array}{l}\text { Prages } \\
\text { 2008 }\end{array}$ & 2007 & 2006 & 2010 & $\begin{array}{c}\text { SER } \\
2009 \\
\end{array}$ & $\begin{array}{l}\frac{p a g e s i}{2008} \\
2008\end{array}$ & $\frac{n \pi R}{2007}$ & 2006 & 2010 & 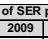 & $\begin{array}{l}\text { pagest } \\
20083\end{array}$ & 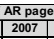 & 20006 & $\frac{\text { onto. }}{2010}$ & $\begin{array}{l}\text { pagesi } \\
2009\end{array}$ & 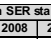 & nation & 2006 & $\frac{180156}{2010 / 2}$ & 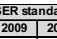 & 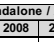 & 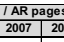 & \begin{tabular}{l|l}
2006 \\
2006
\end{tabular} & \begin{tabular}{l|l}
010 & 2009 \\
\end{tabular} & 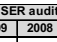 & 4007 & 2006 & 2010 & 2009 & $\begin{aligned} \text { tramewor } \\
02008\end{aligned}$ & 2007 & \\
\hline 188 & green & yes & yes & yes & 144 & 158 & 150 & 154 & \begin{tabular}{|l|l|}
48 \\
\end{tabular} & \begin{tabular}{|l|}
0 \\
\end{tabular} & 0 & 7 & \begin{tabular}{|l|}
0 \\
\end{tabular} & \begin{tabular}{l|l}
8 \\
\end{tabular} & 0,0 & \begin{tabular}{|l|l|}
0,0 \\
\end{tabular} & \begin{tabular}{|l|}
4,7 \\
\end{tabular} & \begin{tabular}{|l|l|}
0,0 \\
\end{tabular} & \begin{tabular}{|l|l|}
16,7 \\
\end{tabular} & 44 & 30 & \begin{tabular}{l|l}
28 &
\end{tabular} & 50 & 66 & $\begin{array}{ll}30,6 & 1\end{array}$ & $\begin{array}{l}19,0 \\
19\end{array}$ & 18.7 & \begin{tabular}{l|l}
32,5 & 13 \\
\end{tabular} & \begin{tabular}{l|l}
137,5 & DN \\
\end{tabular} & \begin{tabular}{l|l|l} 
oNV & DNV
\end{tabular} & $\begin{array}{l}\text { V D DN } \\
\end{array}$ & \begin{tabular}{|l|l|} 
\\
\end{tabular} & \begin{tabular}{|l|} 
DNV \\
\end{tabular} & GRI & GRI & GRl & GRl, UNGC & GRR, UNGC \\
\hline Ath Laval & green & yes & yes & yes & 136 & 136 & 132 & 132 & 120 & 4 & 4 & 6 & 9 & 4 & 2,9 & 2.9 & \begin{tabular}{l|l}
4,5 \\
\end{tabular} & \begin{tabular}{|l|l|}
6,8 \\
\end{tabular} & 3,3 & 16 & 22 & 18 & 14 & 2 & $\begin{array}{ll}11,8 & 1\end{array}$ & $\begin{array}{l}16,2 \\
\end{array}$ & \begin{tabular}{l|l}
13,6 \\
\end{tabular} & \begin{tabular}{l|l}
10,6 & 1
\end{tabular} & \begin{tabular}{|l|l|}
1,7 & $\mathrm{no}$
\end{tabular} & no & \begin{tabular}{|l|l|} 
no \\
\end{tabular} & no & no & GRI & GR, UNGC & GR, UNGC & GRl, UNGC & GRl, UNGC \\
\hline $\begin{array}{l}\text { ASAA ABLOY } \\
\end{array}$ & green & yes & yes & yes & $\begin{array}{l}130 \\
\end{array}$ & 126 & 106 & 102 & 94 & 7 & 7 & 4 & 5 & 4 & 5,4 & 5.6 & \begin{tabular}{ll|}
3,8 \\
\end{tabular} & 4.9 & 4,3 & 48 & 48 & 38 & 42 & 20 & \begin{tabular}{l|l}
36,9 & 3 \\
\end{tabular} & \begin{tabular}{l|l}
38,1 & 3 \\
\end{tabular} & \begin{tabular}{ll|}
35,8 \\
\end{tabular} & \begin{tabular}{l|l}
41,2 & 21 \\
\end{tabular} & \begin{tabular}{|l|l|l}
21,3 & Delo \\
\end{tabular} & $\begin{array}{ll}\text { ilitite } & \text { no }\end{array}$ & no & no & no & GRR, UNGC & GRl, UNGC & GRP, UNGC & GRl, UNGC & no \\
\hline istrazeneca & amber & no & yes & yes & 214 & 212 & 204 & 208 & 52 & 10 & 3 & 3 & ${ }^{4}$ & 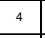 & 4,7 & 1,4 & $\begin{array}{l}1.5 \\
1\end{array}$ & 1,9 & 7,7 & 214 & 166 & c & 0 & 40 & $\begin{array}{lll}100,0 & 7 \\
\end{array}$ & \begin{tabular}{l|l}
78,3 & 0 \\
\end{tabular} & 0,0 & \begin{tabular}{l|l}
0.0 & 76 \\
\end{tabular} & 76,9 & BV & Bv & BV & BV & GRl, UNGC & GR, UNGC & no & no & AA1000 \\
\hline Alas Copco & green & yes & yes & yes & 144 & 144 & 140 & 140 & 124 & 20 & 20 & 18 & 10 & 13 & 13,9 & 13,9 & \begin{tabular}{|l|l|}
12,9 \\
\end{tabular} & 7,1 & 10,5 & 0 & 0 & 0 & 0 & 0 & \begin{tabular}{l|l}
0.0 \\
\end{tabular} & \begin{tabular}{l|l}
0,0 & 0 \\
\end{tabular} & \begin{tabular}{l|l|}
0,0 \\
\end{tabular} & \begin{tabular}{l|l}
0,0 & 0 \\
\end{tabular} & \begin{tabular}{|l|l|l}
0,0 \\
\end{tabular} & Elitite KPMG & 16 KPMC & \begin{tabular}{l|l}
6 & no \\
\end{tabular} & no & GRl, UNGC & GRl, UNGC & GRR, UNGC & GRl, UNGC & GRI \\
\hline Boliden & red & yes & yes & no & 112 & 106 & 100 & 110 & 106 & 1 & 3 & 2 & 4 & 3 & 0.9 & 2,8 & 2,0 & \begin{tabular}{|l}
3,6 \\
\end{tabular} & 2,8 & 57 & 40 & 44 & 46 & 46 & $\begin{array}{ll}50,9 & 3 \\
\end{array}$ & \begin{tabular}{l|l|l}
37,7 & 4 \\
\end{tabular} & $\begin{array}{lll}44,0 & 4\end{array}$ & \begin{tabular}{l|l|l}
41,8 & 43 \\
\end{tabular} & \begin{tabular}{l|l}
43,4 & no \\
\end{tabular} & \begin{tabular}{|l|} 
no \\
\end{tabular} & \begin{tabular}{|l} 
no \\
\end{tabular} & no & no & GRI & GRI & GRI & GRI & GRI \\
\hline Electrolux & amber & yes & yes & yes & 188 & 198 & 178 & 158 & 138 & ${ }_{4}^{4}$ & 16 & 2 & 5 & 5 & 2,1 & 8,1 & 1,1 & 3,2 & 3,6 & 35 & 28 & ${ }^{23}$ & 44 & 42 & 18,61 & \begin{tabular}{l|l}
14,1 & 1 \\
\end{tabular} & $12,9=$ & \begin{tabular}{l|l}
27,8 & 30 \\
\end{tabular} & \begin{tabular}{l|}
30,4 \\
\end{tabular} & no & no & no & no & GRl, UNGC & GRl, UNGC & GRl, UNGC & GRl, UNGC & GRl, UNGC \\
\hline Enicsson & green & yes & yes & yes & 164 & 172 & 176 & 180 & 159 & 0 & 0 & 3 & 2 & 2 & $\begin{array}{l}0.0 \\
\end{array}$ & 0,0 & 1,7 & 1,1 & 1,3 & 115 & 94 & 44 & 44 & 44 & $\begin{array}{ll}0,1 & 5\end{array}$ & \begin{tabular}{l|l|l}
54,7 & 2 \\
\end{tabular} & 25,0 & \begin{tabular}{l|l}
24,4 & 27 \\
\end{tabular} & \begin{tabular}{|l|l|}
27,7 & DN \\
\end{tabular} & \begin{tabular}{|l|l|} 
DNV \\
\end{tabular} & \begin{tabular}{l|l} 
V D N \\
\end{tabular} & DNv & \begin{tabular}{|l|} 
DNV \\
\end{tabular} & GRl, UNGC & GRl, UNGC & GRI, UNGC & GRl, UNGC & GRl, UNGC \\
\hline Getinge & amber & yes & yes & 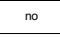 & 110 & 109 & 110 & 102 & 108 & 10 & 7 & 5 & 3 & 2 & 9.1 & 6,4 & 4,5 & \begin{tabular}{|l|}
2,9 \\
\end{tabular} & 1,9 & 0 & 0 & 0 & 0 & 0 & \begin{tabular}{ll|l}
0,0 & \\
\end{tabular} & \begin{tabular}{l|l}
0,0 & 0 \\
\end{tabular} & \begin{tabular}{ll|}
0,0 \\
\end{tabular} & \begin{tabular}{l|l}
0.0 & 0 \\
\end{tabular} & \begin{tabular}{|l|l|}
0,0 & no \\
\end{tabular} & \begin{tabular}{|l|l} 
no \\
\end{tabular} & \begin{tabular}{|l|l} 
no \\
\end{tabular} & no & \begin{tabular}{|l} 
no \\
\end{tabular} & no & no & no & no & no \\
\hline Hennes \& Maunitz, HRM & $\begin{array}{l}\text { amber } \\
\end{array}$ & yes & yes & no & 112 & 108 & 92 & 84 & 80 & 6 & 5 & 5 & 4 & 3 & 5,4 & 4,6 & 5,4 & 4.8 & 3,8 & 167 & 167 & 129 & 83 & 18 & 499,1 & \begin{tabular}{l|l}
154,6 & 14 \\
\end{tabular} & $\begin{array}{lll}140,2 & 9 \\
\end{array}$ & $\begin{array}{ll}98,8 & 22 \\
\end{array}$ & 22,5 & no & no & no & no & GRl, UNGC & GRR, UNGC & GR, UNGC & GRI & no \\
\hline nivestor & amber & no & yes & yes & 146 & ${ }_{132}$ & 117 & 112 & 100 & 3 & 2 & 2 & 2 & 0 & 2,1 & 1,5 & \begin{tabular}{|l|}
1,7 \\
\end{tabular} & 1,8 & 0.0 & 0 & 0 & 0 & 0 & 0 & 0,0 & \begin{tabular}{l|l}
0,0 & 0 \\
\end{tabular} & 0,0 & \begin{tabular}{|l|l|}
0,0 & 0 \\
\end{tabular} & 0,0 & no & no & no & no & no & no & no & no & no \\
\hline Lundin Petroleum & red & no & yes & no & 108 & 96 & 88 & 85 & 98 & 7 & 6 & 5 & 6 & 5 & 6,5 & 6,3 & 5,7 & 7,1 & 5,1 & 0 & 0 & 0 & 0 & 0 & \begin{tabular}{l|l}
0,0 & \\
\end{tabular} & \begin{tabular}{l|l}
0,0 & 0 \\
\end{tabular} & 0,0 & \begin{tabular}{l|l}
0,0 & 0 \\
\end{tabular} & 0,0 & no & no & no & no & UNGC & UNGC & UNGC & UNGC & no \\
\hline Modem Times Group & green & no & yes & yes & 118 & 118 & 134 & 134 & 102 & 1 & 1 & 1 & 1 & 2 & 0.8 & 0,8 & 0,7 & \begin{tabular}{|l|l}
0,7 \\
\end{tabular} & 2,0 & 47 & 0 & 0 & 0 & 0 & 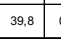 & \begin{tabular}{l|l}
0,0 & 0 \\
\end{tabular} & 0,0 & \begin{tabular}{l|l}
0,0 & 0 \\
\end{tabular} & 0,0 & no & no & no & no & GRI & no & no & no & no \\
\hline Nokia Corporation & green & yes & yes & yes & 126 & 100 & 93 & 92 & 92 & 0 & 0 & $\circ$ & 0 & 0 & 0,0 & 0,0 & 0,0 & 0,0 & 0.0 & 149 & 158 & 114 & 64 & 58 & $\begin{array}{l}18,3 \\
11:\end{array}$ & \begin{tabular}{l|l}
158,0 & 12 \\
\end{tabular} & 122,6 & \begin{tabular}{l|l}
69,6 & 63 \\
\end{tabular} & \begin{tabular}{l|l}
63,0 & PW \\
\end{tabular} & \begin{tabular}{l|l} 
Wc & PWC \\
\end{tabular} & c Pwc & PwC & no & GRR, UNGC & GRR, UNGC & no & no & no \\
\hline Nordea Bank & amber & yes & yes & no & 184 & 173 & 160 & 164 & 155 & 2 & 2 & 2 & 2 & 2 & 1,1 & 1,2 & 1,3 & 1,2 & 1,3 & 44 & 35 & 28 & 8 & 8 & \begin{tabular}{l|l}
23,9 & 2 \\
\end{tabular} & \begin{tabular}{l|l}
20,2 & 1 \\
\end{tabular} & 17,5 & \begin{tabular}{ll|l}
4,9 & 5 \\
\end{tabular} & \begin{tabular}{l|l|l}
5,2 & $\mathrm{KPM}$ \\
\end{tabular} & $\begin{array}{l}\text { PMG } \\
\end{array}$ & 16 KPMC & \begin{tabular}{|l|l|}
6 & no \\
\end{tabular} & no & 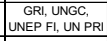 & $\begin{array}{l}\text { GRE, UNCGC, } \\
\text { UNEP HE, UN PRR }\end{array}$ & $\begin{array}{l}\text { GRR, UNDC, } \\
\text { NEP FI, UN PR }\end{array}$ & $\begin{array}{l}\text { GRR UNDC, } \\
\text { NEP FI, UNPR }\end{array}$ & 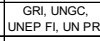 \\
\hline Sanduik & green & yes & yes & yes & 116 & 115 & 111 & 104 & 100 & 12 & 12 & 12 & 8 & 6 & 10,3 & 10,4 & \begin{tabular}{|l|}
10,8 \\
\end{tabular} & \begin{tabular}{|l|l|} 
\\
\end{tabular} & 6,0 & 18 & 18 & 22 & 17 & 17 & \begin{tabular}{l|l}
15,5 & 1 \\
\end{tabular} & \begin{tabular}{l|l}
15,7 & 1 \\
\end{tabular} & $\begin{array}{ll}19,8 \\
\end{array}$ & \begin{tabular}{l|l}
16,3 & 17 \\
\end{tabular} & \begin{tabular}{l|l}
17,0 & KPM \\
\end{tabular} & $\begin{array}{l}\text { PMG } \\
\text { KPMG } \\
\end{array}$ & 16 KPMC & 6 KPMG & no & GRl, AA1000 & GRl, AA1000 & $\begin{array}{ll}\text { GRI } \\
\end{array}$ & GRI & $\begin{array}{ll}\text { GRI } \\
\end{array}$ \\
\hline SCANA & green & yes & yes & yes & 148 & 142 & 142 & 134 & 116 & 12 & 10 & 14 & 10 & 11 & 8,1 & 7,0 & 9,9 & 7,5 & 9,5 & 0 & 0 & 0 & 0 & 0 & $\begin{array}{l}, 0 \\
\end{array}$ & \begin{tabular}{l|l}
0,0 & 0 \\
\end{tabular} & 0,0 & \begin{tabular}{l|l}
0,0 & 0 \\
\end{tabular} & \begin{tabular}{l|l}
0,0 & no \\
0
\end{tabular} & \begin{tabular}{l|l|} 
no & no \\
\end{tabular} & \begin{tabular}{|l|l|} 
no \\
\end{tabular} & no & no & $O E C D$ & OECD & OECD & no & no \\
\hline Secuntas & green & yes & yes & yes & 150 & 144 & 146 & 110 & 130 & 3 & ${ }^{2}$ & ${ }^{2}$ & 2 & ${ }^{3}$ & 2,0 & 1,4 & \begin{tabular}{|l|l|}
1,4 \\
\end{tabular} & \begin{tabular}{|l|}
1.8 \\
\end{tabular} & 2,3 & 2 & $\circ$ & 0 & 0 & $\circ$ & $\begin{array}{l}1,3 \\
\end{array}$ & \begin{tabular}{l|l}
0,0 & 0 \\
\end{tabular} & 0,0 & \begin{tabular}{l|l}
0,0 & 0 \\
\end{tabular} & 0,0 & no & no & no & no & no & no & no & no & no \\
\hline Shandinauska Enskilda Banken & amber & yes & yes & no & 157 & 148 & 140 & 132 & 132 & 2 & 4 & 2 & 2 & ${ }^{2}$ & 1,3 & 2.7 & 1,4 & 1,5 & 1,5 & 49 & 55 & 0 & 0 & 0 & \begin{tabular}{l|l}
31,2 & 3 \\
3
\end{tabular} & \begin{tabular}{l|l}
37,2 & 0 \\
\end{tabular} & 0,0 & \begin{tabular}{|l|l|}
0,0 & 0 \\
\end{tabular} & 0,0 & no & no & no & no & GRl, UNGC & GR, UNGC & GR, UNGC & GRP, UNGC & no \\
\hline Skanska & red & yes & yes & yes & 186 & 172 & 168 & 170 & 148 & 8 & 7 & 7 & 3 & 8 & 4,3 & 4,1 & 4,2 & 1.8 & 5,4 & 0 & 0 & 0 & 0 & 0 & 0.0 & \begin{tabular}{l|l}
0.0 & \\
\end{tabular} & 0,0 & $\begin{array}{l}0,0 \\
0,0\end{array}$ & $\begin{array}{l}0,0 \\
0 \text { KPM }\end{array}$ & \begin{tabular}{l|l|} 
PMG & no \\
\end{tabular} & no & no & \begin{tabular}{|l|} 
no \\
\end{tabular} & UNGC & UNGC & UNGC & UNGC & UNGC \\
\hline SKF & green & no & yes & no & 164 & 156 & 150 & 136 & 132 & 26 & 24 & 25 & 17 & 15 & 15,9 & 15,4 & 16,7 & \begin{tabular}{|l|}
12,5 \\
\end{tabular} & 11,4 & 0 & 0 & 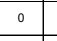 & 0 & $\circ$ & \begin{tabular}{l|l}
0.0 \\
\end{tabular} & $\begin{array}{l}0,0 \\
\end{array}$ & 0,0 & $\begin{array}{l}0,0 \\
0,0 \\
\end{array}$ & $\begin{array}{l}0,0 \\
\text { KPM } \\
\end{array}$ & $\begin{array}{l}\text { PMG } \\
\text { KPMG } \\
\end{array}$ & 16 KPMC & G KPMG & KPMG & $\begin{array}{l}\text { GRE, INACC, } \\
\text { AA 1000 }\end{array}$ & 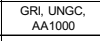 & $\begin{array}{l}\text { GRE, INACC, } \\
\text { AA 1000 }\end{array}$ & $\begin{array}{l}\text { GRR UNGCC, } \\
\text { AA } 1000\end{array}$ & 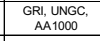 \\
\hline SSAB & green & yes & yes & yes & 126 & 126 & 124 & 104 & 88 & 9 & 9 & ${ }^{10}$ & 5 & 4 & 7,1 & 7,1 & \begin{tabular}{l|l|l}
8,1 \\
\end{tabular} & \begin{tabular}{|l|l}
4,8 \\
\end{tabular} & 4,5 & 46 & 40 & 32 & 0 & 0 & \begin{tabular}{l|l}
36,5 \\
\end{tabular} & \begin{tabular}{l|l}
31,7 & 2 \\
\end{tabular} & 25,8 & \begin{tabular}{|l|l|l|}
0,0 & 0 \\
\end{tabular} & 0,0 & \begin{tabular}{|l|l|} 
no \\
\end{tabular} & \begin{tabular}{|l} 
no \\
\end{tabular} & no & \begin{tabular}{|l|l|} 
no \\
\end{tabular} & GR1 & GRI & GRI & no & no \\
\hline SCA & red & yes & yes & yes & 110 & 110 & 99 & 130 & 118 & 4 & 5 & 1 & 2 & 0 & 3,6 & 4,5 & \begin{tabular}{|l|}
1,0 \\
\end{tabular} & 1,5 & 0,0 & 74 & 78 & 78 & 70 & 70 & 67 & \begin{tabular}{l|l}
70,9 & 7 \\
\end{tabular} & $\begin{array}{ll}78,8 \\
\end{array}$ & \begin{tabular}{|l|l}
53,8 & 5 \\
\end{tabular} & $\begin{array}{l}59,3 \\
\text { PW } \\
\end{array}$ & \begin{tabular}{l|l}
$W C$ & PWC \\
\end{tabular} & C PWC & $\begin{array}{ll}c \text { Pwc } \\
\end{array}$ & PWC & $\begin{array}{l}\text { GRI, UNGC, } \\
\text { EMAS }\end{array}$ & $\begin{array}{l}\text { GR, UNGC } \\
\text { EMAS }\end{array}$ & $\begin{array}{l}\text { GR, UNGC, } \\
\text { EMAS }\end{array}$ & 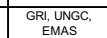 & no \\
\hline \begin{tabular}{|l|} 
Silenska Aandelsbanken \\
\end{tabular} & amber & yes & yes & ${ }^{\text {no }}$ & 176 & 164 & 152 & 136 & ${ }_{132}$ & 6 & 4 & 5 & 3 & 4 & 3,4 & 2,4 & 3,3 & 2,2 & 3,0 & 32 & 0 & 0 & 0 & 0 & \begin{tabular}{ll|}
18,2 \\
\end{tabular} & $\begin{array}{l}0,0 \\
\end{array}$ & 0,0 & 0,0 & 0,0 & \begin{tabular}{l|l} 
no & no \\
\end{tabular} & $\begin{array}{ll}\text { no } \\
\end{array}$ & no & \begin{tabular}{|l|l|} 
no \\
\end{tabular} & $\begin{array}{l}\text { GR, UNGC, UN } \\
\text { PRI }\end{array}$ & no & no & no & no \\
\hline Swedbank & amber & no & yes & no & 184 & 151 & 135 & 124 & 112 & 2 & 4 & 4 & 8 & 4 & 1,1 & 2,6 & 3,0 & 6,5 & 3,6 & 0 & 2 & ${ }^{2}$ & $2^{2}$ & 2 & $\begin{array}{ll}0,0 \\
\end{array}$ & 1,3 & 1.5 & \begin{tabular}{l|l}
1,6 & 1 \\
\end{tabular} & 1,8 & no & no & no & nо & $\begin{array}{l}\text { GRR, UNCGC, } \\
\text { UNEP, UN PRR }\end{array}$ & $\begin{array}{l}\text { PNAC, } \\
\text { PRI }\end{array}$ & $\begin{array}{l}\text { UNNGC, } \\
\text { PRI }\end{array}$ & $\begin{array}{l}\text { UnNCG, } \\
\text { PRI }\end{array}$ & no \\
\hline Swedish Match & amber & yes & yes & no & ${ }_{120}$ & 112 & 112 & 112 & 100 & 18 & 8 & 10 & 9 & 7 & 15,0 & 7,1 & 8,9 & 8,0 & 7,0 & 26 & 0 & 0 & 0 & 0 & 21,7 & $\begin{array}{l}0,0 \\
\end{array}$ & 0,0 & \begin{tabular}{l|l|l|}
0,0 & 0 \\
\end{tabular} & 0,0 & no & no & no & no & GR1 & no & no & no & no \\
\hline \begin{tabular}{|l|l|l|l|l|l} 
Tel \\
\end{tabular} & $\begin{array}{l}\text { green } \\
\end{array}$ & $\begin{array}{l}\text { yes } \\
\end{array}$ & $\begin{array}{l}\text { yes } \\
\end{array}$ & $\begin{array}{l}\text { yes } \\
\end{array}$ & 64 & 61 & 54 & \begin{tabular}{|l|}
88 \\
\end{tabular} & 80 & 2 & 0 & 0 & 0 & 0 & \begin{tabular}{ll|}
, 1, \\
,
\end{tabular} & \begin{tabular}{|l|}
0,0 \\
\end{tabular} & $0,0,0$ & \begin{tabular}{|l|l|}
0,0 \\
\end{tabular} & \begin{tabular}{|l|l}
0,0 \\
\end{tabular} & 20 & 0 & 18 & 0 & 0 & \begin{tabular}{l|l}
31,3 \\
\end{tabular} & \begin{tabular}{l|l}
0,0 & 3 \\
0
\end{tabular} & $\begin{array}{ll}33,3 \\
\end{array}$ & \begin{tabular}{|l|l}
0,0 & 0 \\
\end{tabular} & 0,0 & no & no & no & no & GRI & no & no & no & no \\
\hline Teliasonera & green & no & yes & no & 69 & 106 & 125 & 131 & 104 & 0 & 0 & 4 & 4 & 4 & 0,0 & \begin{tabular}{|l|} 
\\
\end{tabular} & 3,2 & 3,1 & \begin{tabular}{|l|}
3,8 \\
\end{tabular} & 69 & 68 & 73 & 44 & 30 & \begin{tabular}{|l|l|l|l|l|}
10,0 & \\
\end{tabular} & \begin{tabular}{l|l}
64,2 & 5 \\
\end{tabular} & \begin{tabular}{l|l}
58,4 \\
\end{tabular} & \begin{tabular}{|l|l}
33,6 & 2 \\
\end{tabular} & 28,8 & no & no & no & no & GRI & GRI & GRI & GR1 & GRI \\
\hline Volvo & green & yes & yes & yes & 154 & 1466 & 160 & 166 & 170 & 6 & 2 & 4 & 4 & 3 & 3,9 & 1,4 & 2,5 & 2,4 & $\begin{array}{l}1,8 \\
\end{array}$ & 36 & 33 & 24 & 27 & 23 & \begin{tabular}{|l|l|}
23,4 \\
\end{tabular} & \begin{tabular}{l|l}
22,6 & 1 \\
\end{tabular} & \begin{tabular}{l|l|}
15,0 \\
\end{tabular} & \begin{tabular}{|l|l}
16,3 & 1 \\
\end{tabular} & 13,5 & no & no & no & no & GRl, UNGC & GR, UNGC & GRl, UNGC & GR, UNGC & GRR, UNGC \\
\hline & $\Sigma$ & 22 & 29 & ${ }_{18}$ & \begin{tabular}{|l|l|}
4060 \\
\end{tabular} & \begin{tabular}{|l|}
3941 \\
\end{tabular} & 3798 & 3734 & 3238 & 185 & $\begin{array}{ll}167 \\
\end{array}$ & 165 & \begin{tabular}{|l|l|}
134 \\
\end{tabular} & $\begin{array}{l}128 \\
\end{array}$ & & & & & $\Sigma$ & \begin{tabular}{|l|l|}
1308 \\
\end{tabular} & \begin{tabular}{l|l|}
1082 \\
\end{tabular} & 715 & 555 & 486 & & & & & $\Sigma$ & 9 & 9 & 7 & 5 & 23 GRI & $18 \mathrm{GRI}$ & $\begin{array}{ll}16 \mathrm{GRI} \\
\end{array}$ & $16 \mathrm{GPI}$ & 11 GR \\
\hline & & & & & & & & & & & & & & & & & & & & & & & & & & & & & & & & & & 16 UNGC & 16 UNGC & 14 UNGC & 14 UNGC & 8 UnGC \\
\hline & Mean & 0,76 & 1,00 & 0.62 & \begin{tabular}{|l|l|}
140,0 \\
\end{tabular} & \begin{tabular}{|l|l|}
135,9 \\
\end{tabular} & 131,0 & 128,8 & \begin{tabular}{|l|l|}
111,7 \\
\end{tabular} & \begin{tabular}{|l|l|} 
\\
\end{tabular} & 5,76 & 5,69 & \begin{tabular}{|l|}
4,62 \\
\end{tabular} & \begin{tabular}{|l|}
$, 4,41$ \\
\end{tabular} & \begin{tabular}{|l|}
4,62 \\
\end{tabular} & \begin{tabular}{|l|}
4,20 \\
\end{tabular} & \begin{tabular}{|l|}
, 3434 \\
\end{tabular} & \begin{tabular}{|l|l|}
3.74 \\
\end{tabular} & \begin{tabular}{|l|l}
4,27 & 4 \\
\end{tabular} & \begin{tabular}{|l|l|}
45,10 \\
\end{tabular} & 37,31 & \begin{tabular}{|l|l}
24,66 & 1 \\
\end{tabular} & 19,14 & \begin{tabular}{l|l|}
16,76 \\
,
\end{tabular} & \begin{tabular}{|ll}
34,36 & 2 \\
\end{tabular} & \begin{tabular}{l|l}
28,78 & 2. \\
\end{tabular} & \begin{tabular}{l|l}
22,86 & \\
\end{tabular} & \begin{tabular}{|l|l|l|l|}
182 & 18 \\
\end{tabular} & \begin{tabular}{l|l}
18,97 & 1,3 \\
\end{tabular} & \begin{tabular}{|l}
1,31 \\
\end{tabular} & \begin{tabular}{l|l}
1 & 1,31 \\
\end{tabular} & \begin{tabular}{|l|l}
1,24 \\
\end{tabular} & \begin{tabular}{|l}
1,17 \\
\end{tabular} & 2AA10000 & 2AA1000 & 1AA1000 & 1AA1000 & 2AA1000 \\
\hline & stod. Devala & 0,44 & 0,00 & 0,49 & \begin{tabular}{|l|l|}
34,90 \\
\end{tabular} & \begin{tabular}{|l|l|}
32,70 \\
\end{tabular} & 32,26 & \begin{tabular}{ll|}
30,42 \\
\end{tabular} & \begin{tabular}{|l|l|}
28,69 \\
\end{tabular} & \begin{tabular}{|c|c|c|}
6,38 \\
\end{tabular} & 5,595 & \begin{tabular}{|l|l|}
5,64 \\
\end{tabular} & \begin{tabular}{|l|}
3,79 \\
\end{tabular} & \begin{tabular}{|l|}
3,68 \\
\end{tabular} & \begin{tabular}{|l|}
4,52 \\
\end{tabular} & \begin{tabular}{|l|}
4,05 \\
\end{tabular} & \begin{tabular}{|l|}
4,10 \\
\end{tabular} & \begin{tabular}{|l|}
3,06 \\
\end{tabular} & \begin{tabular}{|l|l|l|l|l}
3.87 & 5 \\
\end{tabular} & \begin{tabular}{|l|l|}
54,02 & \\
\end{tabular} & \begin{tabular}{|l|l|}
51,03 \\
\end{tabular} & \begin{tabular}{|l|l|l|}
34,62 & 2
\end{tabular} & \begin{tabular}{l|l}
25,86 &
\end{tabular} & \begin{tabular}{l|l}
22,88 \\
\end{tabular} & \begin{tabular}{|l|l|}
39,56 & 4 \\
\end{tabular} & \begin{tabular}{l|l|l}
42,41 & 3 \\
\end{tabular} & $\begin{array}{ll}36,05 & 22\end{array}$ & \begin{tabular}{|l|l|}
24,96 & 3 \\
\end{tabular} & 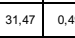 & \begin{tabular}{|l|l|}
0.47 \\
\end{tabular} & \begin{tabular}{l|l}
7 & 0.47 \\
\end{tabular} & 0,38 & \begin{tabular}{|l|l|}
0,30 \\
\end{tabular} & 2 UNEP F1 & 1 UNEP FI & 1 UNEP F1 & 1 UNEP FI & 1 UNEP FI \\
\hline & Green & 0,80 & 1,00 & 0.87 & $\begin{array}{l}130,2 \\
\end{array}$ & \begin{tabular}{|l|l|}
130,0 \\
\end{tabular} & 129,5 & 127,1 & \begin{tabular}{|l|}
110,6 \\
\end{tabular} & \begin{tabular}{|l|l|}
6,80 \\
\end{tabular} & \begin{tabular}{|l|}
6,07 \\
6
\end{tabular} & \begin{tabular}{|l|l|}
7,33 \\
\end{tabular} & \begin{tabular}{|l|l|}
5,13 \\
\end{tabular} & \begin{tabular}{|l|l|}
5,27 \\
\end{tabular} & 4,900 & \begin{tabular}{|l|l|}
4,40 \\
\end{tabular} & \begin{tabular}{|l|l|}
5,38 \\
\end{tabular} & \begin{tabular}{|l|l|} 
\\
\end{tabular} & \begin{tabular}{|l|l|l|}
5,15 & 4 \\
\end{tabular} & \begin{tabular}{|l|l|}
40,67 & \\
\end{tabular} & \begin{tabular}{l|l|}
34,07 & \\
\end{tabular} & \begin{tabular}{|l|l|l|}
27,40 & 2 \\
\end{tabular} & 20,13 & 17,33 & \begin{tabular}{|l|l|}
34,36 & 2 \\
\end{tabular} & \begin{tabular}{c|c}
28,00 & 2. \\
\end{tabular} & \begin{tabular}{l|l}
24,54 &
\end{tabular} & \begin{tabular}{|l|l|l}
16,30 & 20 \\
\end{tabular} & \begin{tabular}{|l|l|l}
20,70 & 0,4 \\
\end{tabular} & \begin{tabular}{|l|l|}
0.40 \\
\end{tabular} & \begin{tabular}{l|l|l}
0 & 0,40 \\
\end{tabular} & \begin{tabular}{|l|l|} 
& 0,33 \\
\end{tabular} & \begin{tabular}{|l|l|}
0,20 \\
\end{tabular} & 3UN PRI & 2UNPRI & 2 UN PRI & 2 UN PRI & 1 UNPRI \\
\hline & Amber & 0.70 & 1.00 & 0,70 & 159,1 & \begin{tabular}{|l|l|}
150,7 \\
\end{tabular} & 140,0 & 133,2 & \begin{tabular}{|l|l|}
110,9 \\
\end{tabular} & 6,30 & \begin{tabular}{|l|}
5,50 \\
\end{tabular} & \begin{tabular}{|l|l|} 
\\
\end{tabular} & \begin{tabular}{|l|}
4,20 \\
\end{tabular} & \begin{tabular}{|l|}
, 30 \\
\end{tabular} & \begin{tabular}{|l|l|} 
\\
\end{tabular} & \begin{tabular}{|l|}
3,82 \\
\end{tabular} & \begin{tabular}{|l|}
3,21 \\
\end{tabular} & \begin{tabular}{|l|l}
3,40 \\
\end{tabular} & \begin{tabular}{|l|l|l|}
3,33 & 5 \\
\end{tabular} & \begin{tabular}{|l|l|l|l|l}
56,70 \\
\end{tabular} & 45,30 & \begin{tabular}{|l|l|l|}
18,20 & 1 \\
\end{tabular} & 13,70 & \begin{tabular}{ll|}
1,00 \\
\end{tabular} & \begin{tabular}{|l|l}
36,27 & 3 \\
\end{tabular} & $\begin{array}{lll}30,58 & 1\end{array}$ & 17,21 & \begin{tabular}{|l|l|l|l|l}
13,31 & 1 \\
\end{tabular} & \begin{tabular}{l|l|l}
13,68 & 0,2 \\
\end{tabular} & \begin{tabular}{l|l}
020 & 0,20 \\
\end{tabular} & \begin{tabular}{l|l}
0 & 0,20 \\
\end{tabular} & \begin{tabular}{|l|l|} 
& 0,10 \\
\end{tabular} & 0,10 & 1 EMAS & 1 EMAS & 1 EMAS & 1 EMAS & 1 EMAS \\
\hline & Red & 0,75 & 1,00 & 0,50 & \begin{tabular}{|l|l|}
129,0 \\
\end{tabular} & \begin{tabular}{|l|}
121,0 \\
\end{tabular} & 113,8 & \begin{tabular}{|l|l|}
123,8 \\
\end{tabular} & \begin{tabular}{|l|l|}
117,5 \\
\end{tabular} & \begin{tabular}{|l|l|}
5,00 \\
\end{tabular} & \begin{tabular}{|l|l|}
5,25 \\
\end{tabular} & 3,75 & \begin{tabular}{|l|}
3,75 \\
\end{tabular} & \begin{tabular}{|l|l|}
4,00 \\
\end{tabular} & \begin{tabular}{|l|}
3,83 \\
\end{tabular} & \begin{tabular}{|l|l|}
4,42 \\
\end{tabular} & \begin{tabular}{|l|}
3,21 \\
\end{tabular} & \begin{tabular}{|l|}
3,50 \\
\end{tabular} & \begin{tabular}{|l|l}
3,33 & 3 \\
\end{tabular} & $\begin{array}{l}32,75 \\
3\end{array}$ & 29,50 & \begin{tabular}{|l|l|l|}
30,50 & 2
\end{tabular} & 29,00 & $29,00 \mid$ & \begin{tabular}{|l|l|l|}
29,54 & 2 \\
\end{tabular} & \begin{tabular}{l|l}
27,16 & 33
\end{tabular} & \begin{tabular}{ll|l}
30,70 & 2
\end{tabular} & \begin{tabular}{|l|l|l|l|}
23,92 &
\end{tabular} & \begin{tabular}{l|l}
25,68 & 0,5 \\
\end{tabular} & \begin{tabular}{l|l|l}
., 50 & 0,25
\end{tabular} & \begin{tabular}{l|l}
5 & 0,25 \\
\end{tabular} & \begin{tabular}{|l|l|}
5 & 0,25 \\
\end{tabular} & 0,25 & 10 OECD & $10 E C D$ & $10 E C D$ & & \\
\hline
\end{tabular}


Table 4 Quantity and location of biodiversity disclosure

\begin{tabular}{|c|c|c|c|c|c|c|c|c|c|c|c|c|c|}
\hline \multirow{2}{*}{ Company } & \multirow{2}{*}{ F\&C zone } & \multirow{2}{*}{$\begin{array}{c}\text { Website - } \\
\text { BioDiv }\end{array}$} & \multirow{2}{*}{\begin{tabular}{l|} 
BioDiv \\
action
\end{tabular}} & \multicolumn{5}{|c|}{ Bio Div narrative in SER } & \multicolumn{5}{|c|}{ BioDiv indicators in SER reports } \\
\hline & & & & 2010 & 2009 & 2008 & 2007 & 2006 & 2010 & 2009 & 2008 & 2007 & 2006 \\
\hline $\mathrm{ABB}$ & green & yes & no & \begin{tabular}{|l|} 
yes \\
\end{tabular} & yes & \begin{tabular}{|l|l|} 
no \\
\end{tabular} & no & no & EN $11-15^{*}$ & EN11-15* & EN $11-15^{*}$ & EN11, EN 12 & EN11, EN 12 \\
\hline Alfa Laval & green & no & no & no & no & no & no & no & no & no & no & \begin{tabular}{|l|} 
no \\
\end{tabular} & \begin{tabular}{|l|} 
no \\
\end{tabular} \\
\hline ASSA ABLOY & green & no & no & no & no & no & no & no & no & no & no & no & no \\
\hline AstraZeneca & amber & yes & yes & yes & yes & no & no & yes & EN 11-14* & EN $11-15^{*}$ & no & no & no \\
\hline Atlas Copco & green & yes & no & yes & no & no & no & yes & no & no & no & no & no \\
\hline Boliden & red & yes & no & yes & no & no & no & yes & EN11-14 & EN11-15 & no & no & EN11, EN 12 \\
\hline Eectrolux & amber & no & no & yes & no & no & no & no & EN 8, EN 11, EN 12 & no & no & no & no \\
\hline Ericsson & green & no & no & no & no & no & no & no & EN $11-15$ & no & no & no & no \\
\hline Getinge & amber & no & no & no & no & no & no & no & no & no & no & no & no \\
\hline Hennes \& Mauritz, H\&M & amber & no & no & no & no & no & no & no & EN 12, EN 14 & no & EN 14 & no & no \\
\hline Investor & amber & no & no & no & no & no & no & no & no & no & no & no & no \\
\hline Lundin Petroleum & red & no & no & yes & no & no & no & no & no & no & no & no & no \\
\hline Modern Times Group & green & no & no & no & no & no & no & no & no & no & no & no & no \\
\hline Nokia Corporation & green & yes & no & yes & yes & no & no & no & $\mathrm{EN} 11, \mathrm{EN} 12$ & $\mathrm{EN} 11, \mathrm{EN} 13$ & EN 11, EN 14 & EN 11, EN 15 & no \\
\hline Nordea Bank & amber & no & no & no & no & no & no & no & no & no & no & no & no \\
\hline Sandvik & green & no & no & no & yes & yes & no & no & no & no & no & no & no \\
\hline SCANIA & green & no & no & no & no & no & no & no & no & no & no & no & no \\
\hline Securitas & green & no & no & no & no & no & no & no & no & no & no & no & no \\
\hline Skandinaviska Enskilda Banken & amber & no & no & no & no & no & no & no & no & no & no & no & no \\
\hline Skanska & red & no & no & yes & no & no & no & no & no & no & no & no & no \\
\hline SKF & green & no & no & no & no & no & no & no & no & no & no & no & no \\
\hline SSAB & green & no & no & no & no & no & no & no & no & no & no & no & no \\
\hline SCA & red & yes & no & yes & yes & yes & no & no & EN11, EN 12 & no & no & no & no \\
\hline Svenska Handelsbanken & amber & no & no & no & no & no & no & no & no & no & no & no & no \\
\hline Sw edbank & amber & no & no & no & no & no & no & no & no & no & no & no & no \\
\hline Sw edish Match & amber & no & no & no & no & no & no & no & no & no & no & no & no \\
\hline Tele2 & green & no & no & no & no & no & no & no & no & no & no & no & no \\
\hline TeliaSonera & green & no & no & no & no & no & no & no & no & no & no & no & no \\
\hline Volvo & green & yes & no & no & no & no & no & no & EN 11-14, EN 15* & no & no & no & no \\
\hline & $\Sigma$ & 7 & 1 & 9 & 5 & 2 & 0 & 3 & 9 & 4 & 3 & 2 & 2 \\
\hline \multirow[t]{6}{*}{ *partially } & & & & & & & & & & & & & \\
\hline & Mean & 1,24 & 1,03 & 1,31 & 1,17 & 1,07 & 1,00 & 1,10 & 1,31 & 1,14 & 1,10 & 1,07 & 1,07 \\
\hline & Std.Dev. & $\overline{0,44}$ & 0,19 & 0,47 & 0,38 & 0,26 & 0,00 & 0,31 & 0,47 & 0,35 & $\overline{0,31}$ & 0,26 & 0,26 \\
\hline & green & 0,27 & 0,00 & 0,20 & 0,20 & \begin{tabular}{|l|}
0,07 \\
\end{tabular} & 0,00 & \begin{tabular}{|l|}
0,07 \\
\end{tabular} & 0,27 & 0,13 & 0,13 & 0,13 & 0,07 \\
\hline & amber & 0,10 & 0,10 & 0,20 & 0,10 & \begin{tabular}{|l|}
0,00 \\
\end{tabular} & 0,00 & \begin{tabular}{|l|}
0,10 \\
\end{tabular} & 0,30 & 0,10 & 0,10 & 0,00 & 0,00 \\
\hline & red & 0,50 & 0,00 & 1,00 & 0,25 & \begin{tabular}{|l|}
0,25 \\
\end{tabular} & 0,00 & 0,25 & 0,50 & 0,25 & 0,00 & 0,00 & 0,25 \\
\hline
\end{tabular}

Chi-Square Test (Fischer's Exact Probability)

\begin{tabular}{|r|c|c|c|c|c|c|c|c|c|c|c|c|}
\hline Likelihood ratio & 2,61 & 2,2 & 10,9 & 0,65 & 2,71 & 0,00 & 0,94 & 0,76 & 0,49 & 1,00 & 2,78 & 2,71 \\
\hline Asymp. Sig. & 0,33 & 0,54 & 0,54 & 0,38 & 0,73 & 0,00 & 0,62 & 0,68 & 0,78 & 0,60 & 0,25 & 0,26 \\
\hline
\end{tabular}

